\title{
The influence of land cover change in the Asian monsoon region on present-day and mid-Holocene climate
}

\author{
A. Dallmeyer ${ }^{1}$ and M. Claussen ${ }^{1,2}$ \\ ${ }^{1}$ Max Planck Institute for Meteorology, KlimaCampus Hamburg, Germany \\ ${ }^{2}$ Meteorological Institute, University of Hamburg, KlimaCampus Hamburg, Germany \\ Received: 16 February 2011 - Published in Biogeosciences Discuss.: 24 February 2011 \\ Revised: 25 May 2011 - Accepted: 30 May 2011 - Published: 10 June 2011
}

\begin{abstract}
Using the general circulation model ECHAM5/ JSBACH, we investigate the biogeophysical effect of largescale afforestation and deforestation in the Asian monsoon domain on present-day and mid-Holocene climate. We demonstrate that the applied land cover change does not only modify the local climate but also change the climate in North Africa and the Middle East via teleconnections. Deforestation in the Asian monsoon domain enhances the rainfall in North Africa. In parts of the Sahara summer precipitation is more than doubled. In contrast, afforestation strongly decreases summer rainfall in the Middle East and even leads to the cessation of the rainfall-activity in some parts of this region.

Regarding the local climate, deforestation results in a reduction of precipitation and a cooler climate as grass mostly has a higher albedo than forests. However, in the core region of the Asian monsoon the decrease in evaporative cooling in the monsoon season overcompensates this signal and results in a net warming. Afforestation has mainly the opposite effect, although the pattern of change is less clear. It leads to more precipitation in most parts of the Asian monsoon domain and a warmer climate except for the southern regions where a stronger evaporation decreases near-surface temperatures in the monsoon season.

When prescribing mid-Holocene insolation, the pattern of local precipitation change differs. Afforestation particularly increases monsoon rainfall in the region along the Yellow River which was the settlement area of major prehistoric cultures. In this region, the effect of land cover change on precipitation is half as large as the orbitally-induced precipitation change. Thus, our model results reveal that mid- to
\end{abstract}

Correspondence to: A. Dallmeyer (anne.dallmeyer@zmaw.de)
late-Holocene land cover change could strongly have contributed to the decreasing Asian monsoon precipitation during the Holocene known from reconstructions.

\section{Introduction}

The effects of large scale deforestation and afforestation have often been analysed in climate model studies. In this context, the biogeophysical consequences of tropical rainforest clearance in single regions like Amazonia, tropical Africa or Southeast Asia as well as total tropical deforestation has widely been discussed (e.g. Henderson-Sellers et al., 1993; Polcher and Laval, 1994; Gedney and Valdes, 2000; Werth and Avissar, 2002, 2005a, b; Findell and Knutson, 2006; Hasler et al., 2009; Snyder, 2010). A few studies also deal with the impact of large-scale extratropical forest cover change on climate (e.g. Bonan et al., 1992; Chalita and Le Treut, 1994; Claussen et al., 2001; Bathiany et al., 2010). Most of these studies agree that tropical forest increases precipitation and cools the local climate compared to lower vegetation, mainly due to an enhanced evaporative cooling. Boreal forests have the opposite effect on temperature since they have a lower albedo than the often snow-covered ground and thus increase the absorption of energy at the surface.

How does climate react to large-scale forest cover changes in the Asian monsoon region? The Asian monsoon region comprises parts of the tropical as well as the temperate climate zone that can even be covered by snow during winter. Due to the heterogeneous orography, including high mountain ranges and parts of the Tibetan Plateau, potential land cover is very diverse. Rainforest grows next to temperate and montane forest; Alpine tundra is located there as well as temperate steppes. 
Monsoon circulations are primarily induced by the thermal contrast between the continent and the ocean, generating large scale pressure gradients (Webster et al., 1998). Therefore, monsoon systems have to be seen as coupled interactive atmosphere-ocean-land phenomena (Yasunari, 2007) in which the land surface plays an equally important part as the ocean. Since land cover changes affect the energy and water balance, they may have a direct influence on the monsoon circulation, moisture convergence and precipitation pattern.

The Asian monsoon system is the strongest monsoon system worldwide. Including large parts of China and India, nearly two thirds of the global population live in the region influenced by this monsoon (Clift and Plumb, 2008). Changes in the monsoonal climate are therefore a matter of particular social, economic and environmental interest. In the last decades, the Asian monsoon region experienced large anthropogenic land cover changes. Huge parts of the natural forest in eastern China have been converted into farmland (e.g. Pongratz et al., 2008). Steppe areas are severely affected by over-grazing and over-farming. Originally vegetated areas in northern China have been overrun by the rapidly expanding deserts. The impact of these land cover change has been analysed in several climate model studies (e.g. Zheng et al., 2002; Fu, 2003; Gao et al., 2007; Zhang and Gao, 2008). They all agree that the vast degradation of the land cover has caused a regional climate change. However, amplitude, sign and distribution of precipitation and temperature change differ and depend on the type of model (regional or global climate model) and the methods for applying the land cover change.

South and East Asia are the homelands of some of the oldest human civilizations. These cultures evolved rapidly and often had advanced agricultural technologies and a well organised urban infrastructure. Particularly the Indus Valley (today's western Pakistan and eastern Afghanistan) and the region around the Yellow River (Fu, 2003; Clift and Plumb, 2008) experienced a long continuing settlement history, starting in the early-Holocene (approx. 7000BC and 6000BC, respectively). The linkage between the development or collapse of theses cultures and the monsoon climate variability as well as the role early human societies could have played for the Holocene climate and environmental change are of special interest in the context of recent global warming. Some studies relate the decline of diverse major prehistoric cultures to intense long-lasting drought spells embedded in the general decreasing Asian summer monsoon since the early- and mid-Holocene (cf. Clift and Plumb, 2008). On the other hand, human interference via forest clearance can not be excluded as a contributing factor to mid- to lateHolocene land cover and climate change either.

Pollen-based vegetation reconstructions suggest that large parts of Central and Eastern China were much more covered by forest during the mid-Holocene. For instance, Ren (2007) suggested an up to $92 \%$ increased forest cover in the middle and lower reaches of the Yellow River for $6 \mathrm{k}(k=1000 \mathrm{yr}$ before present) compared to today, which strongly declined in the following four millennia. According to Ren (2000), the spatial evolution of forest decline in China correlates well with spreading of cultures out of this area. However, Ren (2000) also remarks that this relation can only be a preliminary conclusion due to the lack of well-dated and wellresolved pollen data.

The steppe-forest boundary in East Asia was shifted northwestward by up to $500 \mathrm{~km}$ at $6 \mathrm{k}$ (Yu et al., 2000). Thus, the area around the present-day East Asian monsoon margin experienced a substantial decrease of vegetation in the course of the Holocene. In eastern Inner Mongolia, pollen assemblages reached the maximum Holocene tree pollen fraction $(40-60 \%)$ between $8 \mathrm{k}$ and $5 \mathrm{k}$. Tree pollen decreased in this region to less than $20 \%$ within $2000 \mathrm{yr}$. Also for the nowadays semi-arid north-western Loess Plateau tree pollen dominate the early- to mid-Holocene pollen assemblages, reaching $80 \%$ between $8.5 \mathrm{k}$ to $6.5 \mathrm{k}$. Afterwards, land cover gradually changed to desert with sparse steppe in this region (Zhao et al., 2009).

Less information is known about the vegetation change in the Indian monsoon margin (e.g. Pakistan and north-western India), but also for this area a vegetation loss during the Holocene is supposed (Singh et al., 1990; Ansari and Vink, 2007; Ivory and Lézine, 2009).

These examples of vegetation reconstructions point to the fact that the vegetated area in the Asian monsoon domain was not only characterised by more forests during mid-Holocene but also expanded further inland.

In a previous study, we analysed the contributions of the vegetation-atmosphere interaction, the ocean-atmosphere interaction as well as their synergy to the Holocene climate change in the Asian monsoon region by using a comprehensive Earth system model with dynamic vegetation included (Dallmeyer et al., 2010). This study showed a rather small contribution of the simulated vegetation change on Asian monsoon climate. The mid-Holocene to pre-industrial climate change was predominantly caused by the response of the atmospheric circulation to the insolation forcing as well as oceanic feedbacks. The synergy effect was mostly negligible. Presumably, the model underestimated the amplitude of Holocene forest cover changes which could explain the weak vegetation impact. At least compared to the former pollenbased vegetation reconstructions (see above) the simulated vegetation change seemed to be too small.

Since the simulated vegetation change has only revealed a weak effect on climate, we decide to confront the model with a strong forest cover change to assess the maximum effect of large-scale land-cover changes on the climate in the Asian monsoon domain.

For this purpose, we perform idealised sensitivity experiments with either a complete forest cover or a complete grass cover prescribed in the monsoon region. The domain of land cover change is aligned to Holocene vegetation and human development. The resulting climate change is then presented 
Table 1. Physical properties and phenology type of each plant functional type (PFT), i.e. LAImax: maximum value of the leaf area index; $\alpha_{\mathrm{VIS}}$ : albedo in the visible solar spectrum; $\alpha_{\mathrm{NIR}}$ : albedo in the near infrared solar spectrum; $z_{0}$ : roughness length of vegetation.

\begin{tabular}{llcccr}
\hline PFT & phenology & $\begin{array}{c}\text { LAImax } \\
{\left[\mathrm{m}^{2} \mathrm{~m}^{-2}\right]}\end{array}$ & $\alpha_{\mathrm{VIS}}$ & $\alpha_{\mathrm{NIR}}$ & $\begin{array}{r}z_{0} \\
{[\mathrm{~m}]}\end{array}$ \\
\hline tropical evergreen forest & raingreen & 7 & 0.03 & 0.22 & 2.0 \\
tropical deciduous forest & raingreen & 7 & 0.04 & 0.23 & 1.0 \\
extratropical evergreen forest & evergreen & 5 & 0.04 & 0.22 & 1.0 \\
extratropical deciduous forest & summergreen & 5 & 0.05 & 0.25 & 1.0 \\
raingreen shrubs & raingreen & 3 & 0.05 & 0.25 & 0.5 \\
deciduous shrubs & summergreen & 2 & 0.05 & 0.28 & 0.5 \\
C3 grass & grass & 3 & 0.08 & 0.34 & 0.05 \\
C4 grass & grass & 3 & 0.08 & 0.34 & 0.05 \\
\hline
\end{tabular}

on the basis of precipitation and temperature differences to a control run with present-day potential vegetation.

Secondly, we analyse the remote effect these land cover changes have on precipitation in North Africa and the Middle East. Thirdly, we address the question what information we can deduce from these results regarding the relation of mid-Holocene climate, vegetation and neolithic cultures in the Asian monsoon region.

\section{Model and experiments}

To analyse the influence of large-scale land cover change on the Asian monsoon climate, different sensitivity experiments are performed. In this study, we use the general circulation model ECHAM5 (Roeckner et al., 2003) coupled to the landsurface-scheme JSBACH (Raddatz et al., 2007). Both models have been developed at the Max-Planck-Institute for Meteorology. ECHAM5 run with 31 vertical levels and a spectral resolution of T63, which corresponds to a grid-box width of $1.875^{\circ}$ (i.e. ca. $210 \mathrm{~km}$ on a great circle). JSBACH differentiates eight plant-functional types (PFTs). Forests can contain tropical and/or extratropical trees, which are either evergreen or deciduous. Shrubs are distinguished as raingreen shrubs or cold (deciduous) shrubs. Grass is classified as either $\mathrm{C} 3$ or $\mathrm{C} 4$ grass. The land surface in JSBACH is tiled in mosaics, so that several PFTs can cover one grid cell. Each grid cell also contains non-vegetated area representing the fraction of seasonally bare soil and permanently bare ground (desert).

The global distribution of vegetation in the standard version of JSBACH is based on the potential vegetation map of Ramankutty and Foley (1999) that had been translated into the eight different PFTs of JSBACH. The global distribution of deserts follows the distribution described in the Global Land Cover Characteristics data base of the US Geological Survey (Loveland et al., 2000).
For each PFT and also the bare ground, individual physical properties such as albedo or roughness length are defined (Table 1). JSBACH calculates dynamically the physical land surface parameters (e.g. albedo or roughness length) in each grid-cell as average of the individual properties of the PFTs and the non-vegetated area, weighted with their respective cover fraction. In the calculation of the albedo, snowcovered soils and snow-covered forest-canopies as well as the masking of snow-covered soils by forests are additionally accounted for. The soil albedo is prescribed from satellite data and does not change during the simulations. The albedo of leaves depends on the leaf area index that is calculated on the basis of temperature, soil moisture and the net primary production of the PFTs. Concerning phenology, JSBACH differentiates the four types evergreen, raingreen, summergreen and grasses. LAI can not exceed a maximum value specified for each PFT (see Table 1).

The fluxes of energy, water and momentum between the land and the atmosphere are calculated as described in Roeckner et al. (2003) with the exception that JSBACH uses the aggregated land surface parameter of each grid-cell for the calculation. Surface and atmosphere are coupled implicitly. For further details on the coupling of land-surface schemes (e.g. JSBACH) and general circulation models see Polcher et al. (1998).

The models have been tested against observations and reanalysis data proving that they capture the major structure of global and regional climate (see Appendix A).

With regard to the results of our previous study (cf. Dallmeyer et al., 2010), we assume a weak synergy of the vegetation-atmosphere and ocean-atmosphere interactions. To exclude a contribution of changes in ocean parameters to the climate signal, we prescribe pre-industrial sea surface temperatures and sea-ice cover in all simulations. Both have been extracted from a coarse resolution experiment, performed with the comprehensive Earth System Model ECHAM5/JSBACH-MPIOM. This model included the dynamic ocean model MPIOM (Marsland et al., 2003; 


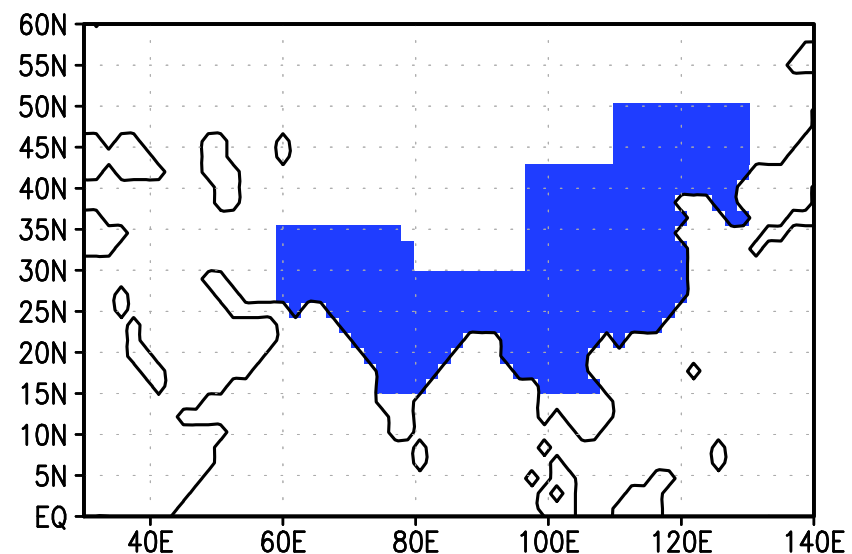

Fig. 1. Extended Asian monsoon region (shaded). In this region, land cover is changed either to forest or to grass in the afforestation and deforestation experiment, respectively.

Jungclaus et al., 2006). Atmospheric composition is kept constant at pre-industrial values; $\mathrm{CO}_{2}$-concentration is set to $280 \mathrm{ppm}$.

Under these boundary conditions, three experiments with differently prescribed land cover in an extended Asian monsoon region (see Fig. 1) are conducted: these are a control run with standard, potential land cover (CTRL), an experiment with forest in the entire region (FOR) and an experiment with grass cover in the entire region (GRA). Thereby, the region was selected combining the following criteria: we extend the Asian monsoon domain by including areas where previous model results have suggested a strong increase of vegetation for mid-Holocene orbital conditions to get a representative monsoon domain for the Holocene (cf. Dallmeyer et al., 2010). Vegetation is not changed in high-elevated areas where the mean orography in the model exceeds $4500 \mathrm{~m}$. Furthermore, the region incorporates areas where humans settled in early- and/or mid-Holocene, i.e. the region includes the Indus Valley, Northeast China and the Chinese provinces Shandong, Hebei, Shanxi, Shaanxi and parts of Gansu and Qinghai.

In the afforestation experiment (FOR), land cover is prescribed as forest in the entire region. In those grid-boxes that have already been forested in the standard land surface map, the ratio between the different tree types is kept constant and the forest sum is scaled to $100 \%$ fraction per grid-box. In grid-boxes without forest vegetation in the standard map, forest is prescribed to $50 \%$ evergreen and $50 \%$ deciduous trees. Trees are prescribed as extratropical or tropical to the north or south of $30^{\circ} \mathrm{N}$, respectively.

The same method is applied in the deforestation experiment (GRA). For grid-boxes already containing grass PFTs in the standard map, the ratio between $\mathrm{C} 3$ and $\mathrm{C} 4$ grass is fixed and total grass sum per grid-box is scaled to $100 \%$ coverage. Regions not containing grass PFTs in the stan- dard map are covered by $20 \% \mathrm{C} 3$ and $80 \% \mathrm{C} 4$ grass south of $30^{\circ} \mathrm{N}$ and $80 \% \mathrm{C} 3$ and $20 \% \mathrm{C} 4$ grass north of $30^{\circ} \mathrm{N}$.

The difference between the land cover in the afforestation or deforestation experiment and the control run can be seen in Fig. 2 for the vegetation types forest, shrubs and grass. The total change of vegetated area as well as the change in fraction covered by shrubs is identical for both experiments.

Each experiment spans 102 yr to get significant results despite of the high natural climate variability in the Asian monsoon system. Since carbon cycle dynamics are not included and the vegetation distribution is prescribed, only the first two years of the simulations are considered as spin-up time and excluded from the analysis. The presented plots show results exceeding the $95 \%$-significance level of a standard student's t-test.

\section{Results}

The period of a reversed upper-tropospheric temperature gradient between $5^{\circ} \mathrm{N}$ and $30^{\circ} \mathrm{N}$ is often taken as a definition for the Asian monsoon season ( $\mathrm{Li}$ and Yanai, 1996; Webster et al., 1998; Ye and Wu, 1998). According to this definition, the length of the monsoon season in our experiments remains unaffected regardless of which land cover is prescribed (not shown). Based on the month of earliest simulated onset and latest simulated withdrawal in the Asian monsoon domain we therefore divide our analyses period into two different seasons. These are the monsoon season (lasting from May to October) and the dry/cold season (lasting from November to April). Furthermore, we concentrate on precipitation and near-surface air temperature as the main parameters describing monsoonal influenced climates. The results presented in this study are based on $100 \mathrm{yr}$-means, averaged over the respective season.

\subsection{Effect of land cover change on precipitation}

\subsubsection{Afforestation experiment}

The significant effect of a prescribed forest cover on seasonal mean precipitation is illustrated in Fig. 3. The land cover change predominantly has a local and only weak effect on precipitation. Monsoon precipitation is increased particularly on the south-central Tibetan Plateau (up to $0.77 \mathrm{~mm} \mathrm{day}^{-1}$ ). In north-eastern China (approx. $0.35 \mathrm{~mm} \mathrm{day}^{-1}$ ) as well as at the monsoon margin zone in Inner Mongolia (approx. $0.17 \mathrm{~mm} \mathrm{day}^{-1}$ ), precipitation is also enhanced. In contrast, the western Tibetan Plateau receives less precipitation (up to $0.26 \mathrm{~mm} \mathrm{day}^{-1}$ ) in the afforestation experiment. At the Yangtze delta and parts of the Great Plain of China as well as in South India rainfall is reduced by up to $0.35 \mathrm{~mm} \mathrm{day}^{-1}$ and $0.43 \mathrm{~mm} \mathrm{day}^{-1}$, respectively. 

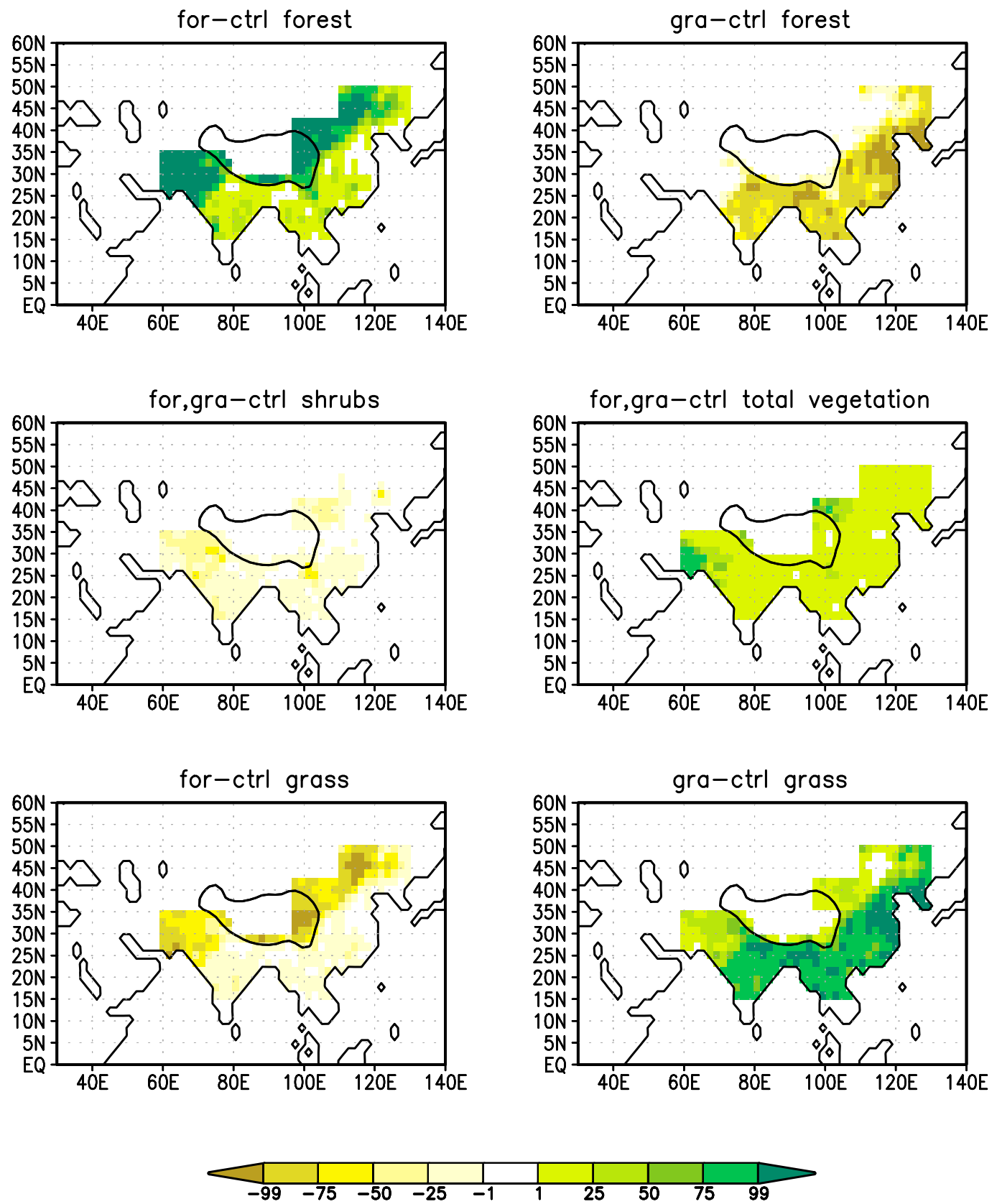

Fig. 2. Differences in forest, shrubs, grass and total vegetation distribution between the land cover map prescribed in the afforestation experiment (for) or the deforestation experiment (gra) and the control run (ctrl). Values are given in fraction per gridbox.

In the dry/cold season, the land cover change causes a significant increase of precipitation on the Tibetan Plateau (ca. $0.39 \mathrm{~mm} \mathrm{day}^{-1}$ ) and in north-eastern China (ca. $0.09 \mathrm{~mm} \mathrm{day}^{-1}$ ). Less precipitation occurs in the region west and north of the Tian Shan (up to $0.23 \mathrm{~mm} \mathrm{day}^{-1}$ ).

\subsubsection{Deforestation experiment}

Complete grass cover in the Asian monsoon region instead of present-day potential vegetation leads to a decrease in monsoon precipitation in a broad band in South and East Asia, including the Yangtze-Huanghe-plain, Indochina, Bay of Bengal, parts of the Tibetan Plateau and East India (Fig. 3). The maximum reduction in monsoon rainfall $\left(2.3 \mathrm{~mm} \mathrm{day}^{-1}\right)$ occurs on the south-eastern edge of the Tibetan Plateau. In contrast, monsoonal precipitation increases slightly, but significantly on the western Tibetan Plateau, reaching $0.26 \mathrm{~mm} \mathrm{day}^{-1}$ at most. 

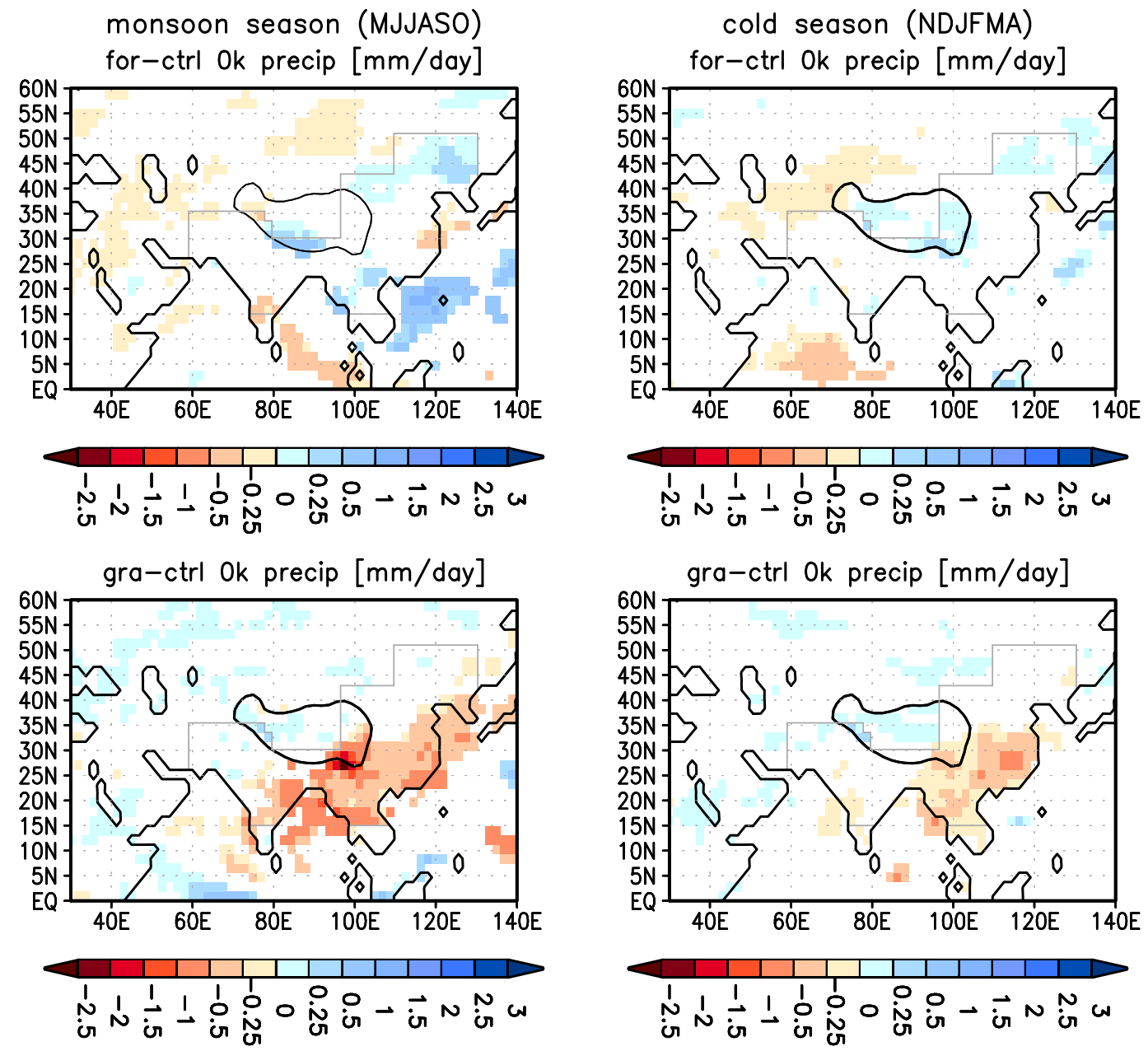

Fig. 3. Simulated precipitation change between the afforestation (for) or deforestation (gra) experiment and the control run (ctrl), averaged over the monsoon season (left panel) and the dry/cold season (right panel). The monsoon season lasts from May to October, the dry/cold season contains the month from November to April. Values are given in mm day ${ }^{-1}$. Only values exceeding the $95 \%$-significance level (t-test) are shown.

In the dry/cold season, the strong precipitation reduction is confined to Eastern China (up to $0.56 \mathrm{~mm} \mathrm{day}^{-1}$ ) and the Indochinese Peninsula (up to $0.35 \mathrm{~mm} \mathrm{day}^{-1}$ ). The central and western Tibetan Plateau receives more precipitation, in particular the western Himalaya with up to $0.3 \mathrm{~mm}_{\text {day }}{ }^{-1}$.

\subsection{Effect of land cover change on near-surface air temperature}

\subsubsection{Afforestation experiment}

Figure 4 shows the significant effect of afforestation on nearsurface air temperature. In the monsoon season, the regions north of $30^{\circ} \mathrm{N}$ that experience a strong afforestation reveal a warmer climate. Temperature increases up to $0.58 \mathrm{~K}$ in Inner Mongolia and north-eastern China, up to $0.4 \mathrm{~K}$ on the eastern Tibetan Plateau and up to $0.65 \mathrm{~K}$ southwest of and on the western Tibetan Plateau. South of $30^{\circ} \mathrm{N}$ temperatures tend to decrease. The land cover change leads to significant cooling in some parts of the Indian West coast and southeast of the Tibetan Plateau (up to $-0.3 \mathrm{~K}$ ).

In the dry/cold season, $2 \mathrm{~m}$-temperature is particularly increased in Northeast China (up to $2.2 \mathrm{~K}$ ) and on the southern flank of the Tibetan Plateau (up to $2.1 \mathrm{~K}$ ). Eastern China, including the eastern Tibetan Plateau, North India, and the region north of the Arabian Sea experience a warmer climate (up to $0.4 \mathrm{~K}$ ). Only at a few grid-boxes southeast of the Tibetan Plateau temperatures slightly decrease by up to $-0.25 \mathrm{~K}$.

\subsubsection{Deforestation experiment}

In the deforestation experiment, monsoon season temperatures are lower in Northeast China (up to $0.35 \mathrm{~K}$ ), Inner Mongolia (ca. $0.2 \mathrm{~K}$ ) and on the Tibetan Plateau (up to $0.55 \mathrm{~K}$ ) compared to the control run (Fig. 4). In contrast, 

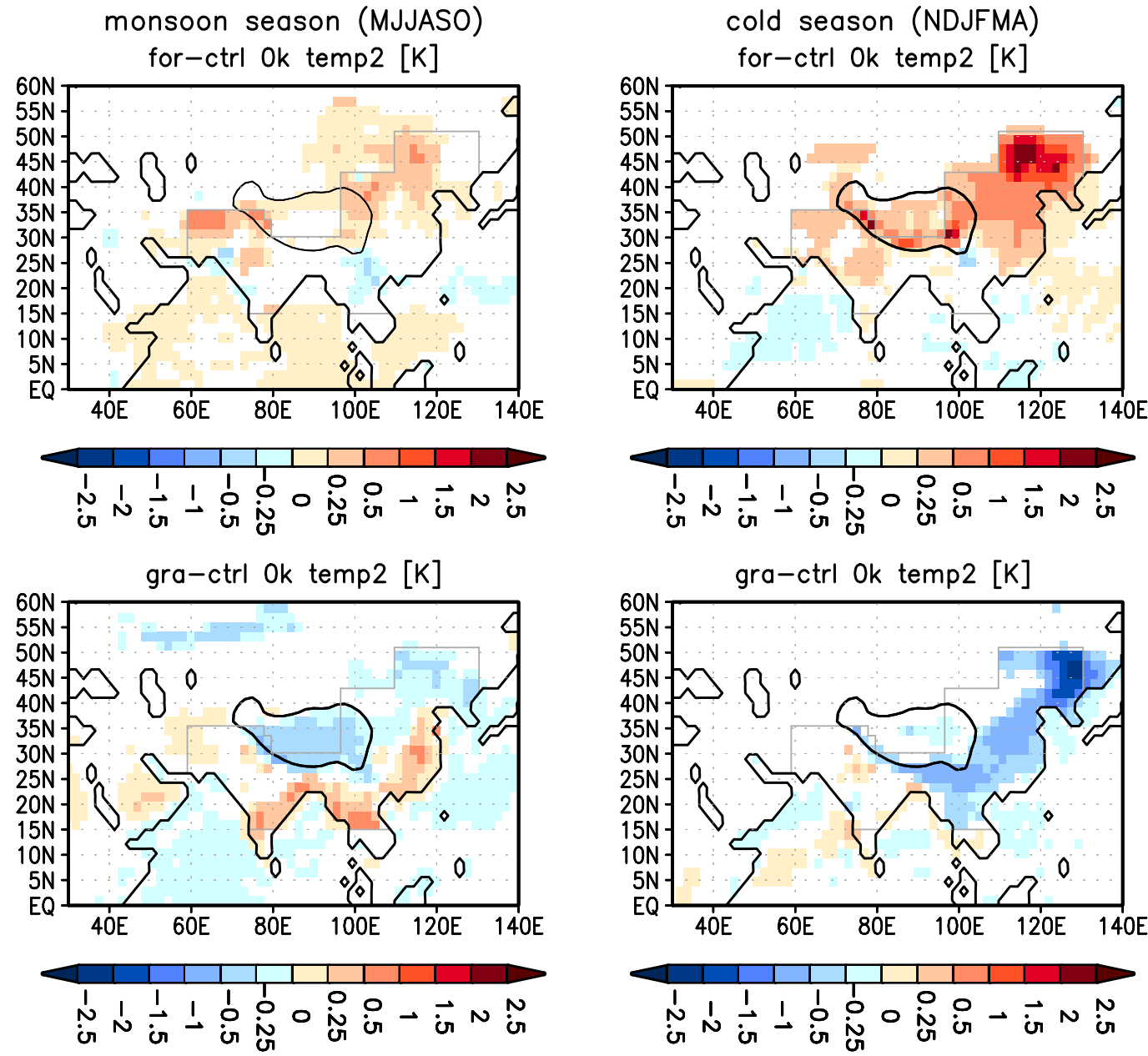

Fig. 4. Simulated near-surface air temperature (in $2 \mathrm{~m}$ height) change between the afforestation (for) or deforestation (gra) experiment and the control run (ctrl), averaged over the monsoon season (left panel) and the dry/cold season (right panel). The monsoon season lasts from May to October, the dry/cold season contains the month from November to April. Values are given in K. Only values exceeding the $95 \%$-significance (t-test) are shown.

the deforested regions south of $25^{\circ} \mathrm{N}$ experience a warming. Temperatures increase by up to $0.9 \mathrm{~K}$ in northern Thailand. Higher temperatures are also found in eastern China, particularly at and around the Great Plain (up to $0.6 \mathrm{~K}$ ).

With prescribed grass cover, dry/cold season temperatures are lower in whole eastern China. The cooling is particularly pronounced in regions, which experience a strong deforestation, e.g. the Great Plain (ca. 0.7 K). Nevertheless, the strongest temperature decline occurs in Northeast China (up to $-2.2 \mathrm{~K}$ ). Climate becomes slightly warmer in the north of India by up to $0.25 \mathrm{~K}$. At the deforested southern flank of the Tibetan Plateau, near-surface air-temperature decreases (ca. $-0.8 \mathrm{~K})$.

\section{Discussion}

The land surface can force the atmosphere via the physical quantities snow cover, soil moisture and vegetation (Yasunari, 2007). In the context of this study, the effect of vegetation change on climate is most important, though vegetation change also indirectly can influence the other parameters. The land cover controls the energy balance at the surface via albedo and roughness length and influences the evapotranspiration. Modifications of the energy fluxes can lead to changes in temperature, pressure field and circulation (Pielke et al., 1998). Modifications of the evaporation due to land cover changes together with circulation changes affect the precipitation distribution. Therefore, we start this chapter with a discussion of the energy and water balance change related to the applied afforestation and deforestation. 

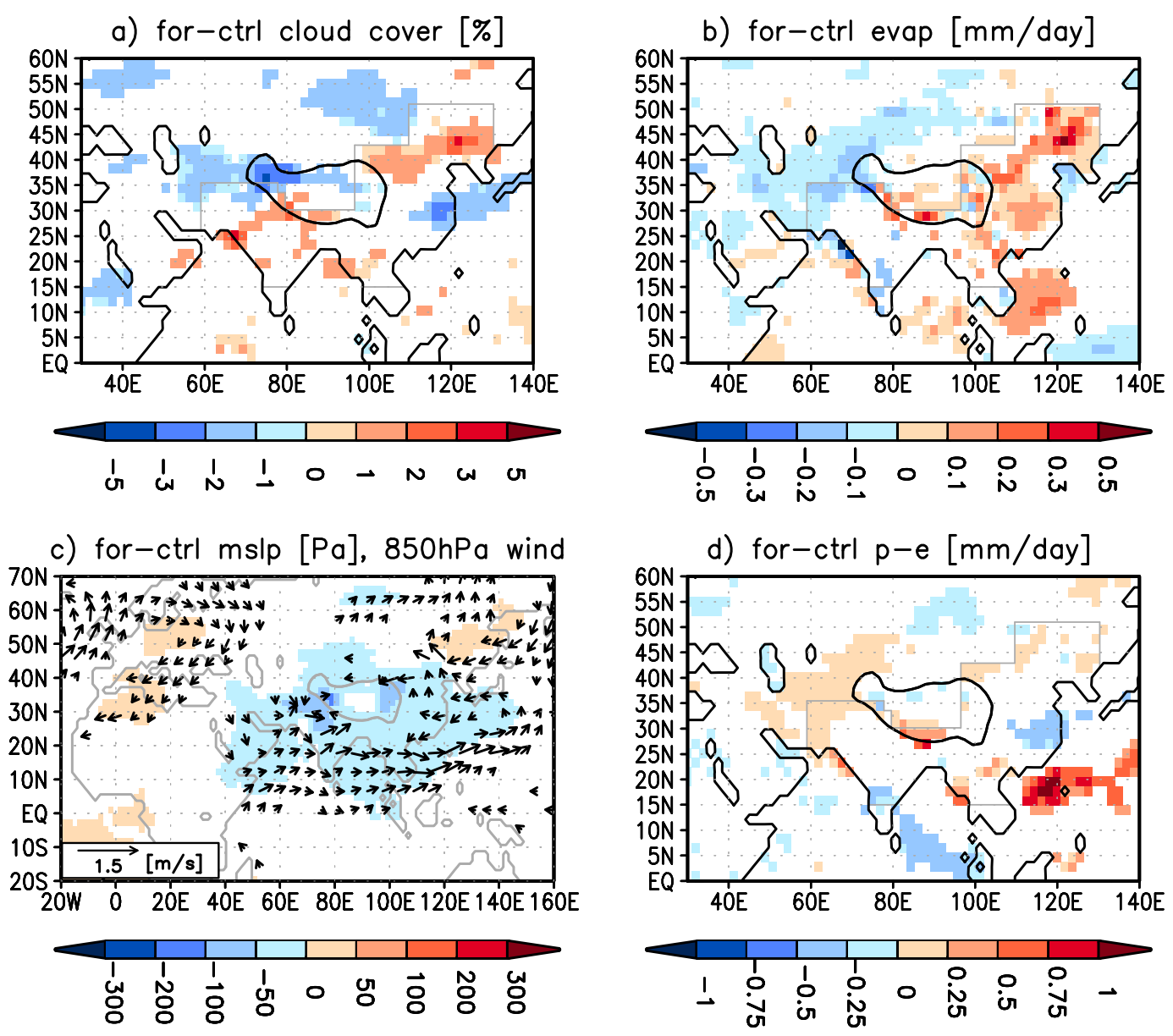

Fig. 5. Simulated change of different parameters influencing the precipitation change between the afforestation experiment (for) and the control run (ctrl), averaged over the monsoon season. (a) total cloud cover in \%; (b) evaporation in mm day ${ }^{-1}$; (c) mean sea level pressure in $\mathrm{Pa}$, shaded, combined with $850 \mathrm{hPa}$ wind in $\mathrm{m} \mathrm{s}^{-1}$, vector; (d) precipitation-evaporation in mm day ${ }^{-1}$ as approximation of the moisture convergence. Except for the wind-field, only values exceeding the $95 \%$-significance level in a standard student's t-test are shown. Instead, wind-vectors are masked out when their magnitude is smaller than one-tenth of the maximum vector length (here: $0.15 \mathrm{~m} \mathrm{~s}^{-1}$ ).

\subsection{Change of circulation and water balance}

\subsubsection{Afforestation experiment}

The Asian monsoon circulation is primarily driven by the seasonal differential heating between the Asian continent and the Indian and Pacific Ocean. During the summer monsoon season, a deep surface heat low covers the region between the Arabian peninsula and the Chinese East coast with lowest pressure in North India and Pakistan. In consequence of the afforestation, the monsoon trough deepens by up to $-120 \mathrm{~Pa}$ in North India (Fig. 5c). Therefore, the Indian monsoon is slightly strengthened, which at least contributes to the enhanced precipitation over southern Himalaya.

In North and Northeast China, the precipitation increase coincides with an enhanced cloudiness (up to $3 \%$, Fig. 5a) and an increased evaporation (up to $0.56 \mathrm{~mm} \mathrm{day}^{-1}$, see Fig. 5b), probably indicating an enhanced water recycling in that region. The shift in cloud cover from the Great Plain
- Japan region to North/Northeast China suggests a shift of the East Asian summer monsoon rain band, i.e. a northwestward extension or shift of the region influenced by the monsoon. This would also explain the reduction of precipitation at the Great Plain and surroundings. The approximation for the moisture convergence (precipitation-evaporation (pe), Fig. 5d) reveals a negative anomaly (i.e., a moisture source) in that region. The extension of the monsoon is consistent with the wind field showing a slight enhancement of the East Asian summer monsoon flow.

During the dry/cold season, the high pressure system in North China is weakened by up to $-100 \mathrm{~Pa}$ (Fig. 6c). Therefore, the strong southward flow in eastern China characterising the East Asian winter monsoon is also weakened. The pressure anomaly induces an anticyclonic wind anomaly with a core in the Yellow Sea which brings warm and wet air-masses to Northeast China. This seems to lead to more clouds and more precipitation in that region. 
a) for-ctrl cloud cover [\%]

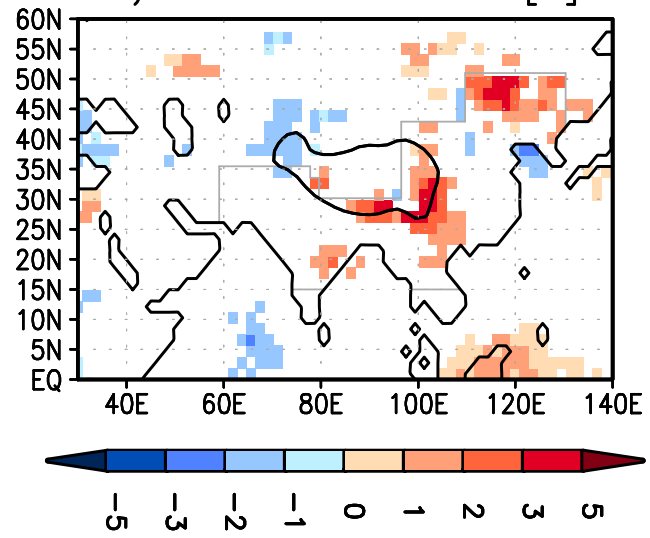

c) for-ctrl mslp $[\mathrm{Pa}], 850 \mathrm{hPa}$ wind

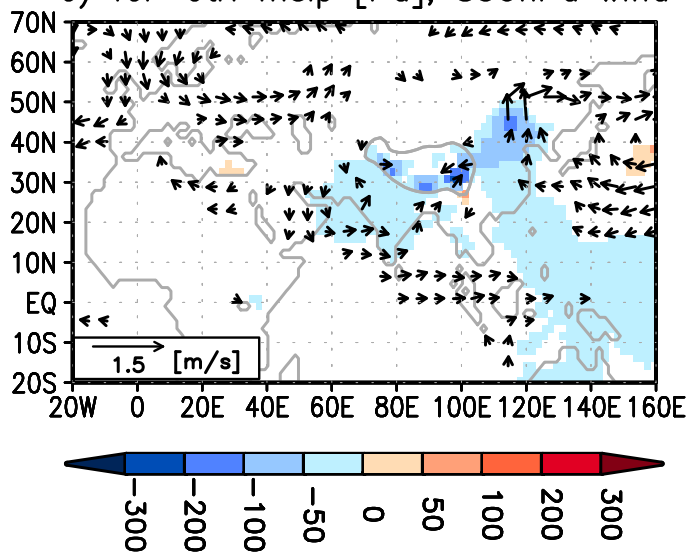

Fig. 6. Same as Fig. 5, but for the dry/cold season.

The increase of precipitation on the Eastern Tibetan Plateau coincides with an enhanced cloudiness (up to $4 \%$ ) and an increased evaporation (up to $0.38 \mathrm{~mm} \mathrm{day}^{-1}$ ) as well as a mean sea level low pressure anomaly (up to $-220 \mathrm{~Pa}$ ). The latter leads to a wind anomaly from the Bay of Bengal to the continent, probably contributing to the precipitation change.

\subsubsection{Deforestation experiment}

Deforestation leads to an attenuation of the Indian and East Asian summer monsoon flows (Fig. 7c). This circulation change is associated with a high pressure anomaly forming in South and Central Asia, in particular on the Tibetan Plateau (up to $110 \mathrm{~Pa}$ ). High pressure anomalies are often related to descending motion and thus indicate less favourable conditions for the formation of precipitation. As a result, monsoon related convection, precipitation and also evaporation in south/south-eastern Asia is reduced (Fig. 7). Total cloud cover decreases by up to $5 \%$, evaporation decreases by up to $0.78 \mathrm{~mm} \mathrm{day}^{-1}$. In contrast, the increase of precipitation on the western Tibetan Plateau is accompanied by more evaporation (up to $0.3 \mathrm{~mm} \mathrm{day}^{-1}$ ) and more clouds (up to $4.5 \%$ ). b) for-ctrl evap $[\mathrm{mm} /$ day $]$

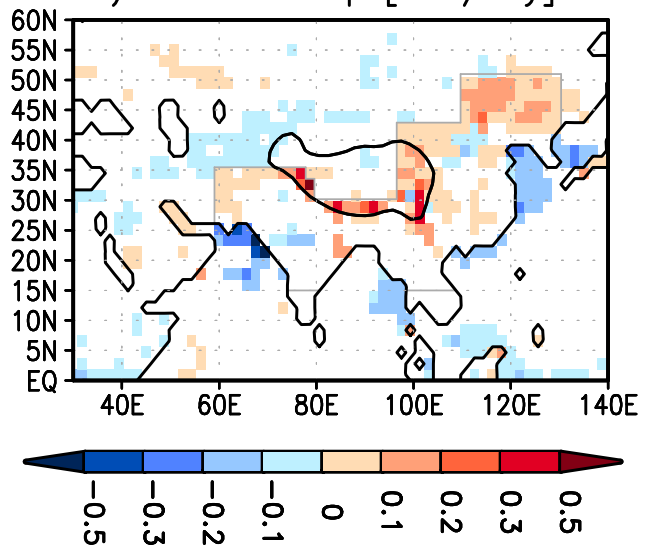

d) for $-c \operatorname{trl} p-e[\mathrm{~mm} / \mathrm{day}]$

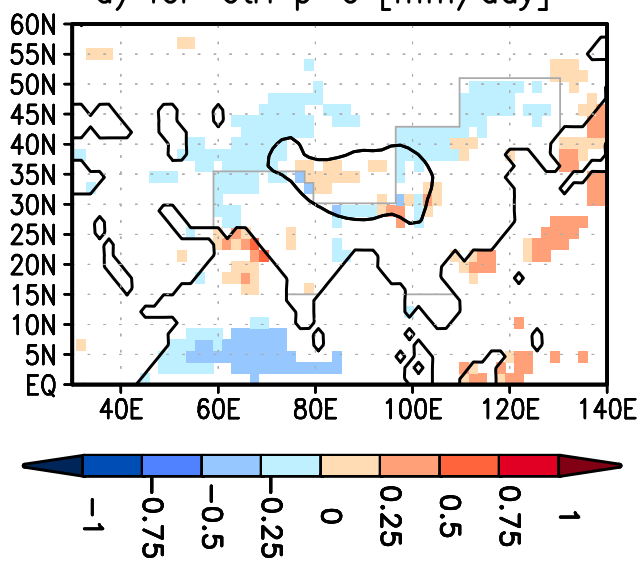

During the dry/cold season the moisture flux is more divergent in eastern China than in the control experiment (Fig. 8). In addition, evaporation rate and cloud cover are reduced by up to $0.52 \mathrm{~mm} \mathrm{day}^{-1}$ and up to $4 \%$, respectively. Both indicate a weaker local moisture recycling and weaker moisture convergence being responsible for the precipitation decline in that area. The precipitation increase on the western Tibetan Plateau is associated with more clouds ( $2 \%)$ and moisture convergence.

\subsection{Change of albedo and turbulent heat fluxes}

\subsubsection{Afforestation experiment}

In the monsoon season, afforestation leads to a decrease of albedo by up to $9.5 \%$ (Fig. 9a). This results in an increase of the absorbed incoming shortwave radiation, which explains the increase of near-surface air temperature in Northeast China, Inner Mongolia as well as in the region southwest of the Tibetan Plateau. The additional shortwave radiation at the surface is mainly transported to the atmosphere by the sensible heat flux. The region of decreased near-surface temperature southeast of the Tibetan Plateau is associated 
a) gra-ctrl cloud cover [\%]

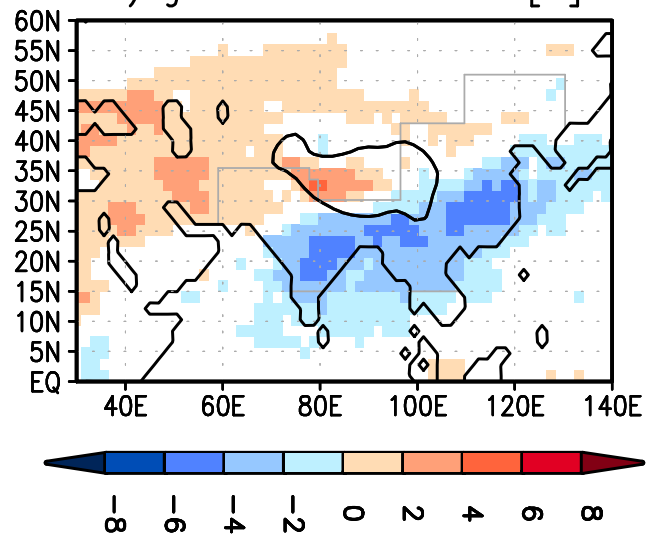

c) gra-ctrl mslp $[\mathrm{Pa}], 850 \mathrm{hPa}$ wind

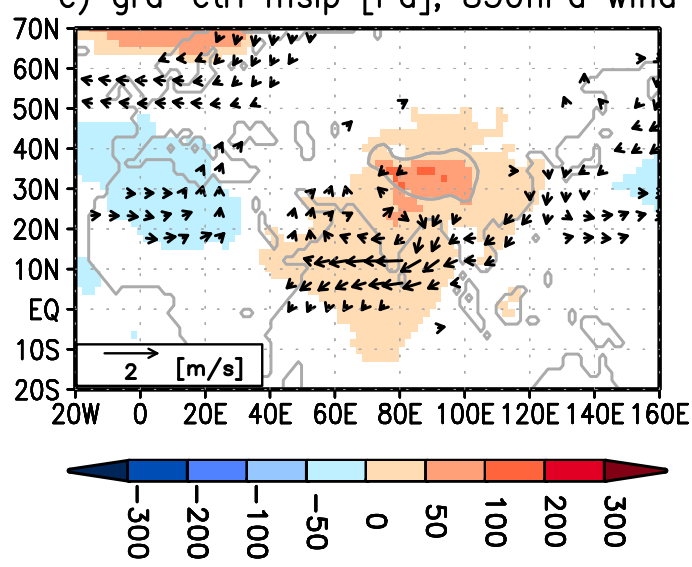

b) gra-ctrl evap $[\mathrm{mm} /$ day $]$

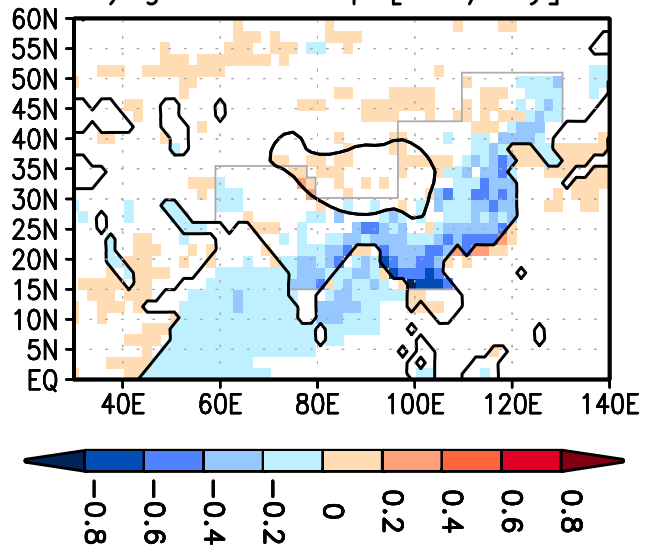

d) $\operatorname{gra}-\operatorname{ctrl} \mathrm{p}-\mathrm{e}[\mathrm{mm} / \mathrm{day}]$

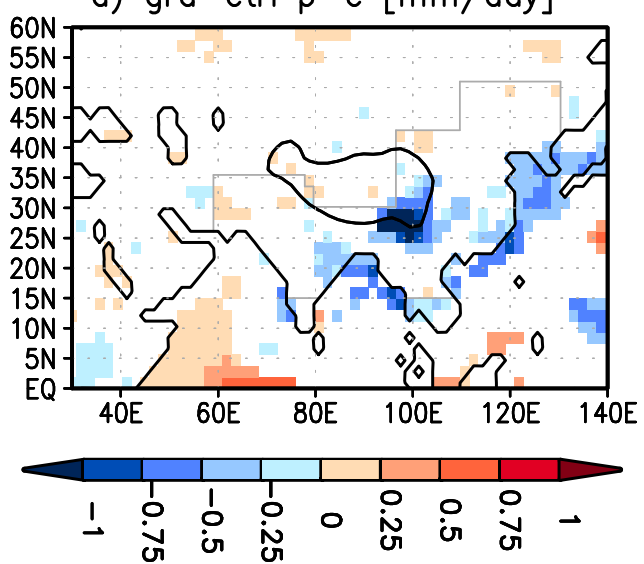

Fig. 7. Simulated change of different parameters influencing the precipitation change between the deforestation experiment (gra) and the control run (ctrl), averaged over the monsoon season. For further details see Fig. 5. Limit for wind-magnitude to be shown: $0.2 \mathrm{~m} \mathrm{~s}^{-1}$.

with a region of less net shortwave radiation at the surface (ca. $6.5 \mathrm{~W} \mathrm{~m}^{-2}$ ), which is probably induced by more clouds (not significant) and a slight albedo increase in that region. At least partly, the increased evaporation/latent-heat flux (up to $5 \mathrm{~W} \mathrm{~m}^{-2}$ ) and the decrease of sensible heat flux (up to $8.5 \mathrm{~W} \mathrm{~m}^{-2}$ ) contribute to lower temperatures in this region due to an increase in evaporative cooling (Fig. 9).

The strong warming in Northeast China and on the Tibetan Plateau in the dry/cold season is induced by a strong albedo decrease (up to $20 \%$ and $35 \%$, respectively, Fig. 10a) which leads to a strong increase of net shortwave radiation at the surface (up to $18 \mathrm{~W} \mathrm{~m}^{-2}$ and $55 \mathrm{~W} \mathrm{~m}^{-2}$ ). These regions are covered by snow in winter, so that the snow-masking effect of the additional forests might contribute to the strong albedo decrease.

In the region southeast of the Tibetan Plateau, the temperature decrease coincides with less net shortwave radiation at the surface (up to $-6 \mathrm{~W} \mathrm{~m}^{-2}$ ), which probably results from an enhanced cloud cover (up to $3 \%$ ).

\subsubsection{Deforestation experiment}

The replacement of forest with grass cover in the Asian monsoon domain increases the albedo by up to $8 \%$ during the monsoon season (Fig. 11a). Nevertheless, near-surface air temperatures in Southeast China and the regions south of $25^{\circ} \mathrm{N}$ are higher in the deforestation than in the control experiment. This is mainly a consequence of less precipitation/evaporation and less cloud cover in that region (cf. Fig. 7a, b) which overcompensate the effect of increased albedo on the near-surface temperature.

The lower temperatures on the Tibetan Plateau are induced by less net solar energy at the surface (up to $-11 \mathrm{~W} \mathrm{~m}^{-2}$ ), mainly due to more clouds (up to $4.5 \%$ ). Stronger evaporative cooling contributes to the lower temperatures on the western Himalaya. In Northeast China, the temperature decrease results from both, less net shortwave radiation at the surface $\left(-6 \mathrm{~W} \mathrm{~m}^{-2}\right)$ due to an albedo increase of up to $5 \%$ as well as a higher evaporative cooling. 
a) gra-ctrl cloud cover [\%]

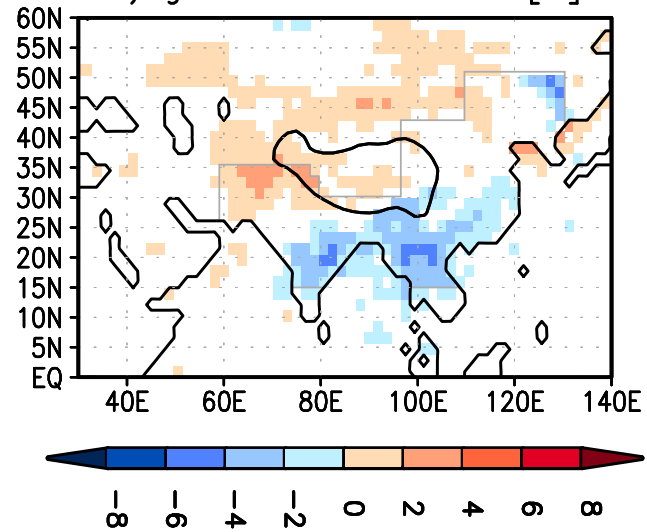

c) gra-ctrl mslp $[\mathrm{Pa}], 850 \mathrm{hPa}$ wind

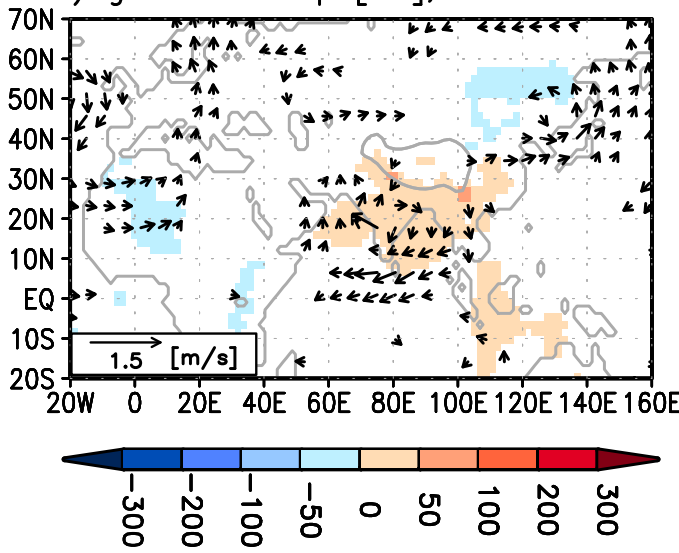

b) gra-ctrl evap $[\mathrm{mm} /$ day $]$

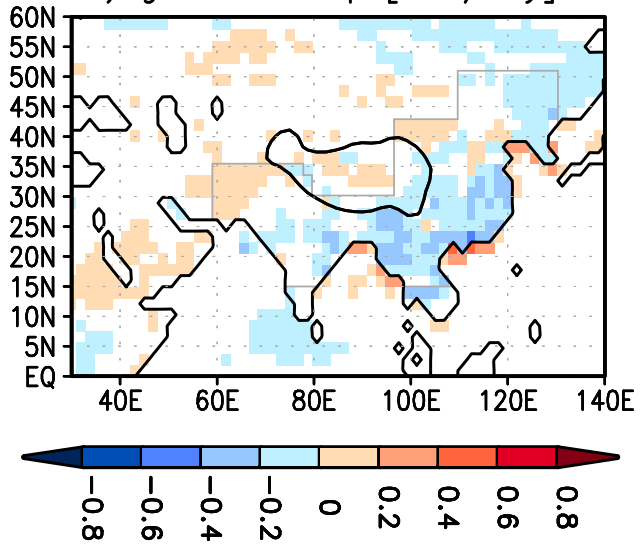

d) $\operatorname{gra}-\operatorname{ctrl} p-e[\mathrm{~mm} /$ day $]$

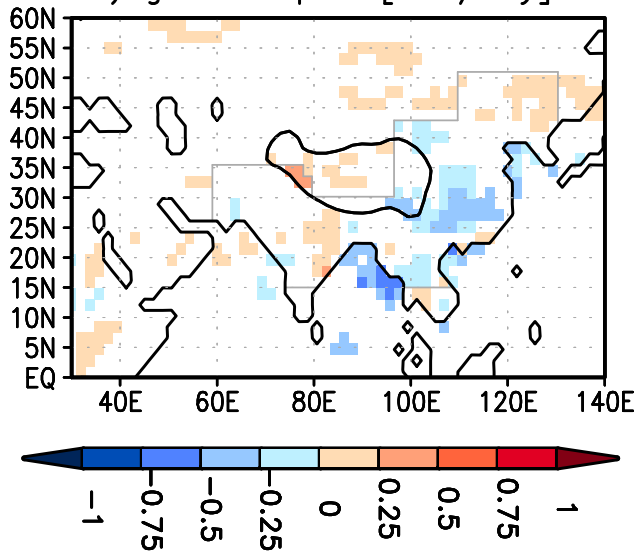

Fig. 8. Same as Fig. 7, but for the dry/cold season. Limit for wind-magnitude to be shown: $0.15 \mathrm{~m} \mathrm{~s}^{-1}$.

In the dry/cold season, deforestation leads to an up to $25 \%$ increase of albedo in the eastern part of Northeast China (Fig. 12), which results in less net shortwave radiation at the surface (up to $-20 \mathrm{~W} \mathrm{~m}^{2}$ ). This part of China is usually covered by more snow than the other parts of the Asian monsoon domain. Therefore, the lack of snow-masking by trees as well as a possibly enhanced snow-albedo feedback in the deforestation experiment may play an important role in decreasing the near-surface-temperature in this region.

\subsection{Comparison to other model studies}

The experimental design and research questions of our study and previous studies that analyse land cover changes in the Asian monsoon region (and parts of it) strongly differ. While previous studies mainly focus on the impact of recent anthropogenic land use change on the regional climate in China our study assesses the maximum effect of large-scale forest cover change on the climate in the entire Asian monsoon domain. Our study does not aim to represent the actual land cover change of the past decades. It is a sensitivity study on the general effect of large-scale deforestation and afforestation in the Asian monsoon region on climate. Furthermore, in most of the previous studies, regional climate models were used. The Asian monsoon system is very complex and involves large-scale circulation systems which strongly determine the precipitation distribution. Regional climate models can not capture the impact of vegetation changes on the largescale circulation and, thus, may not capture the entire effect of vegetation on the regional climate change.

So far, no other publications exist prescribing complete forest or grass cover in the Asian monsoon domain, but our results show similar climate signals received in previous studies performing land cover change experiments. Like in studies with tropical deforestation, precipitation in our simulation decreases when grass cover is prescribed instead of potential present-day vegetation (cf. e.g. Werth and Avissar, 2005a). These studies also report that less forest cover in tropical regions leads to a warmer local climate (cf. e.g. Polcher and Laval, 1994). Increased near-surface air temperatures are also simulated in our deforestation experiment in the regions with a rather tropical climate, i.e. the region ca. south of approx. $26^{\circ} \mathrm{N}$ and Southeast China, in the monsoon season. Outside of this area, temperature decreases as a 
a) for-ctrl albedo [\%]

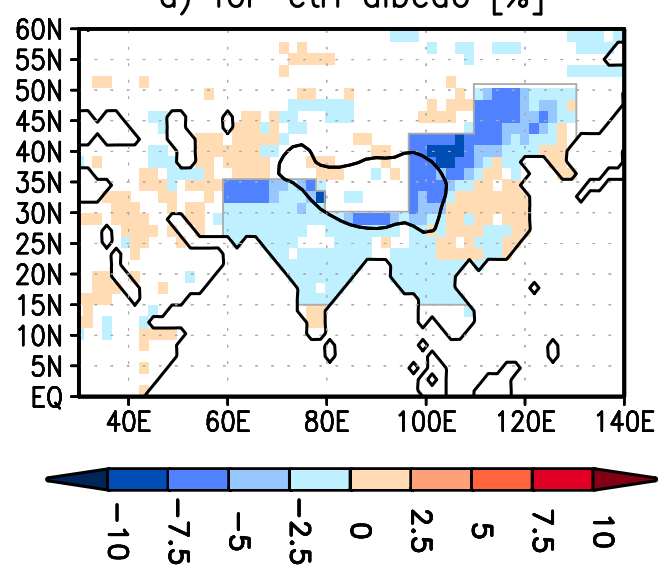

c) for-ctrl lat. heat $\left[\mathrm{W} / \mathrm{m}^{\wedge} 2\right]$

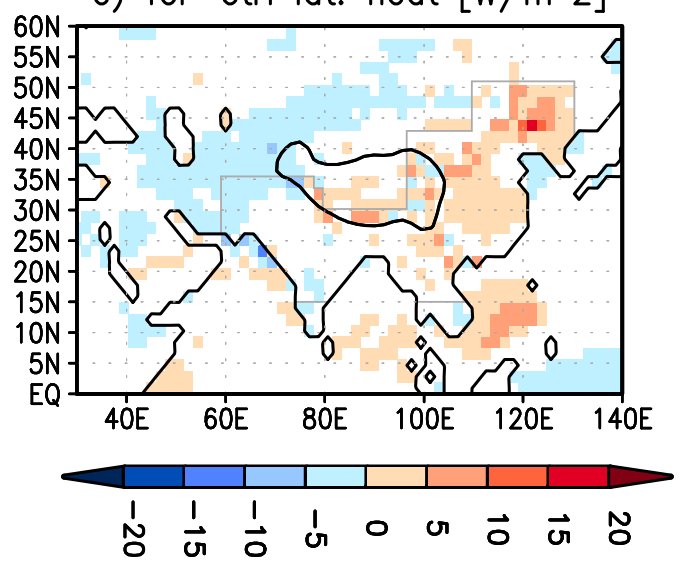

b) for-ctrl SWnet_surf $\left[\mathrm{W} / \mathrm{m}^{\wedge} 2\right]$

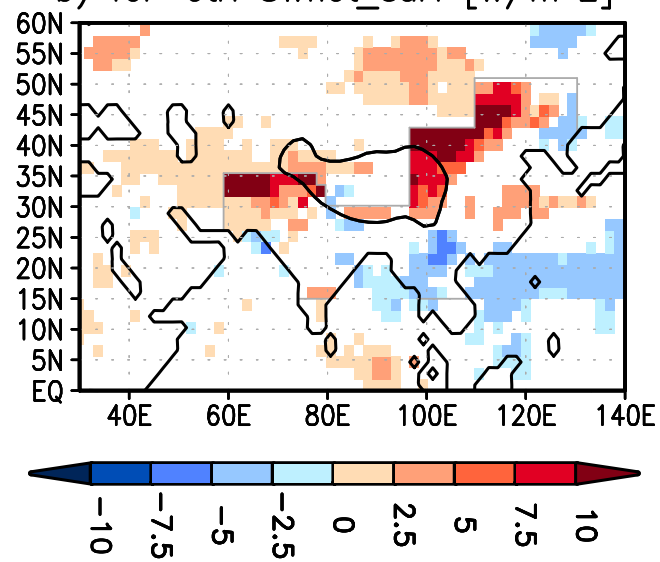

d) for-ctrl sens. heat $\left[\mathrm{W} / \mathrm{m}^{\wedge} 2\right]$

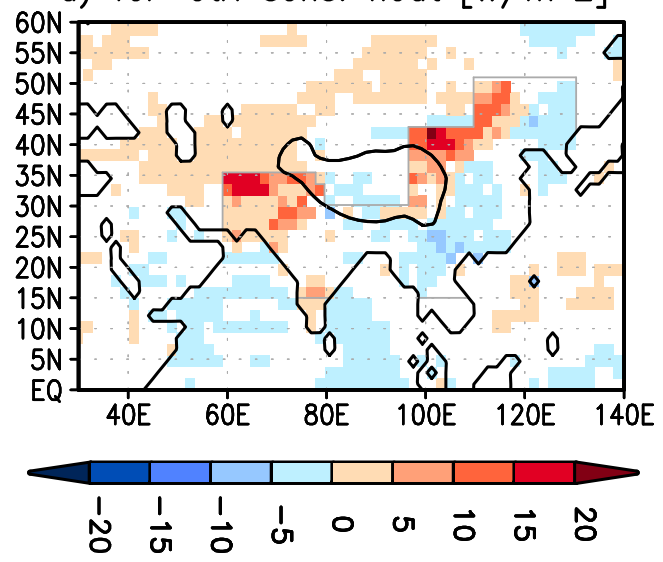

Fig. 9. Simulated change of different parameters influencing the temperature change between the afforestation experiment (for) and the control run (ctrl), averaged over the monsoon season. (a) surface albedo in \%; (b) net surface shortwave radiation in $\mathrm{W} \mathrm{m}{ }^{-2}$; (c) latent heat flux in $\mathrm{W} \mathrm{m}^{-2}$; (d) sensible heat flux in $\mathrm{W} \mathrm{m}^{-2}$.

consequence of forest loss. This response is in line with previous studies of extratropical deforestation (Bonan, 2008). The results from our afforestation experiment reveal a similar pattern of precipitation change as model studies which analyse the effect of present-day land use change in China. For instances, Gao et al. (2007) have compared results from simulations with potential vegetation cover and observed land cover in China by using a regional climate model. Their results show that the vegetation conversion from forest to farmland reduces summer precipitation in northern and western China and enhance precipitation in Southeast China. Similar results were deduced by Zheng et al. (2002) by prescribing simultaneous vegetation degradation in the northern Chinese prairies and the southern evergreen forests. Furthermore, precipitation increases at the Indian East coast. The forest loss between our afforestation experiment and the control run leads to a similar precipitation change in the monsoon season.

\subsection{Remote effect on precipitation in North Africa and the Middle East}

Rodwell and Hoskins (1996) showed in an idealised model study that Asian monsoon related diabatic heating can induce descent in south-western Asia, the Arabian Peninsula and northern Africa via the initiation of Rossby-waves. Other studies emphasise the important role of diabatic heating on the Tibetan Plateau by forming desert climate in North Africa, Central Asia and the Middle East (e.g. Ye and Wu, 1998; Duan and $\mathrm{Wu}, 2005)$. As a consequence of this link, land cover change in the Asian monsoon domain may affect the climate in these regions as it has a strong influence on the energy balance. We address the possible remote effect of land cover change by analysing precipitation change in the monsoon season.

Figure 3 already reveals that the land cover change prescribed in this model study has predominantly a local and only weak influence on precipitation regarding the change 
a) for-ctrl albedo [\%]

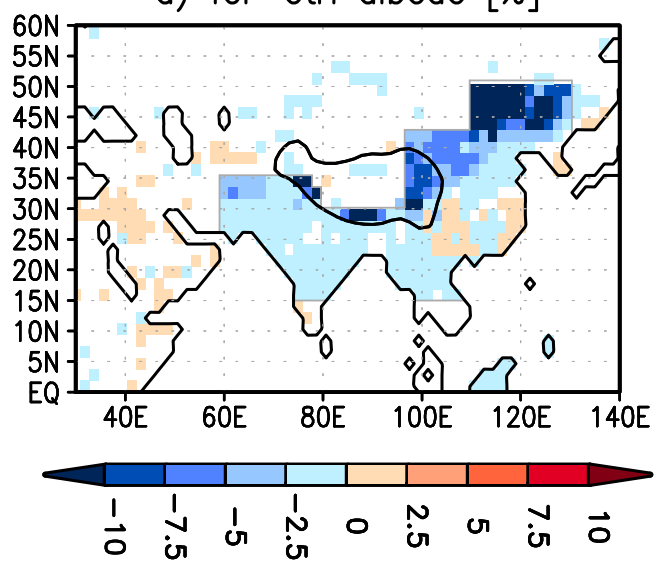

c) for-ctrl lat. heat $\left[\mathrm{W} / \mathrm{m}^{\wedge} 2\right]$

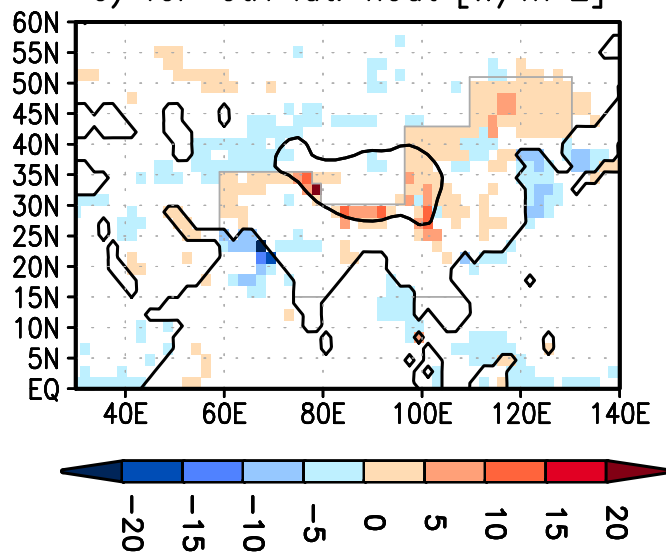

Fig. 10. Same as Fig. 9, but for the dry/cold season.

of absolute precipitation amount. But, when looking at the relative precipitation change the anomaly can be very large. Figure 13 illustrates the change in monsoon season precipitation rate weighted by the current (ctrl) precipitation rate. Afforestation has a strong influence on precipitation in North Arabia, East Egypt and the region around the Southern Caspian Sea. Precipitation is more than halved in a large area. In many places, precipitation even decreases by 80 $100 \%$. The upper-tropospheric velocity-potential anomaly suggests that this change results from an increase in upperlevel wind convergence, enhancing the descending motion and suppressing convective precipitation. In contrast, no significant large-area precipitation change occurs in the North African monsoon region and the Sahara.

Deforestation in the Asian monsoon region leads to a significant increase of precipitation in large parts of North Africa. In the Sahel zone precipitation amount rises by more than $10 \%$, in the eastern Sahel even by more than $50 \%$. The west coastal regions receive more than $25 \%$ more precipitation. In the central Sahara precipitation is more than doubled. Besides, precipitation rate is increased in the north-eastern

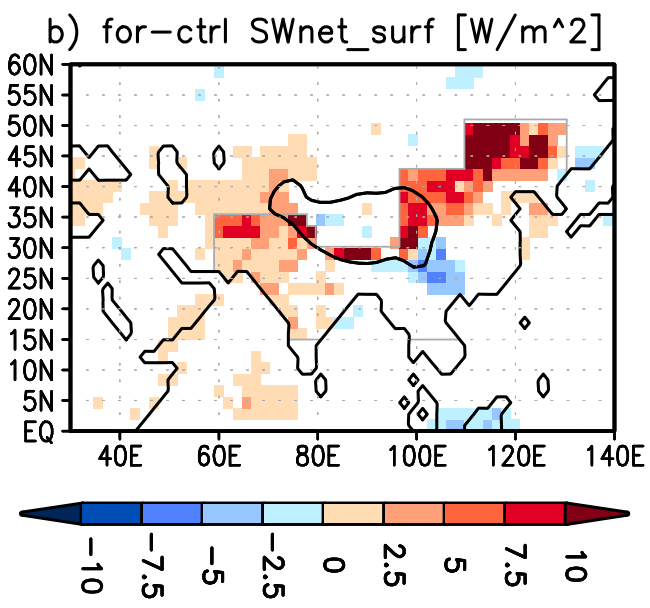

d) for-ctrl sens. heat $\left[\mathrm{W} / \mathrm{m}^{\wedge} 2\right]$

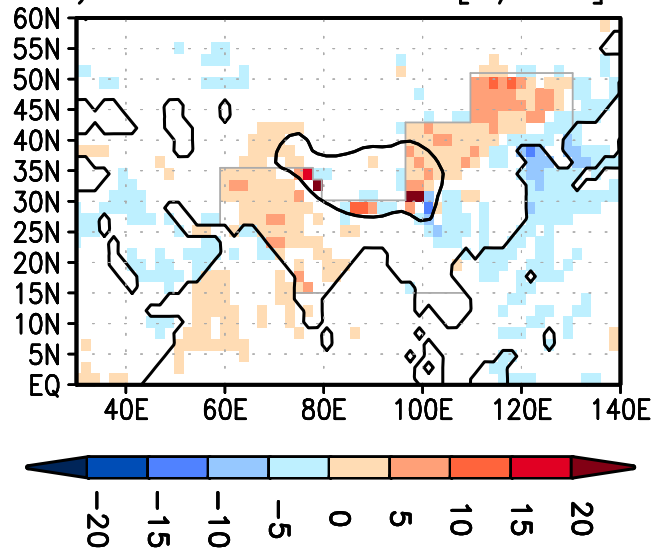

Mediterranean by $20 \%-30 \%$. Figure 7 shows that the deforestation leads to a low-pressure anomaly of up to $33 \mathrm{~Pa}$ in Northern Africa. Therefore, the heat low in the Sahara is expanded and deepened. This induces an enhanced low-level flow from the ocean to the continent, bringing more moisture to the Sahara and Sahel. Furthermore, a reduced convergence in the upper troposphere above Africa and the Mediterranean (Fig. 13) facilitate the formation of deep convection and precipitation.

\subsection{Effect of idealised forest-cover change on mid-Holocene climate}

During mid-Holocene, large parts of the Asian monsoon domain were covered by more forest and the forested and vegetated region expanded further inland compared to present-day (e.g. Yu et al., 2000; Ren and Beug, 2002; Ren, 2007; Herzschuh et al., 2010). Pollen-based vegetation reconstructions reveal broad land-cover degradation since that period (e.g. Zhao et al., 2009). These changes are often related to the decrease in Asian monsoon strength (e.g. 

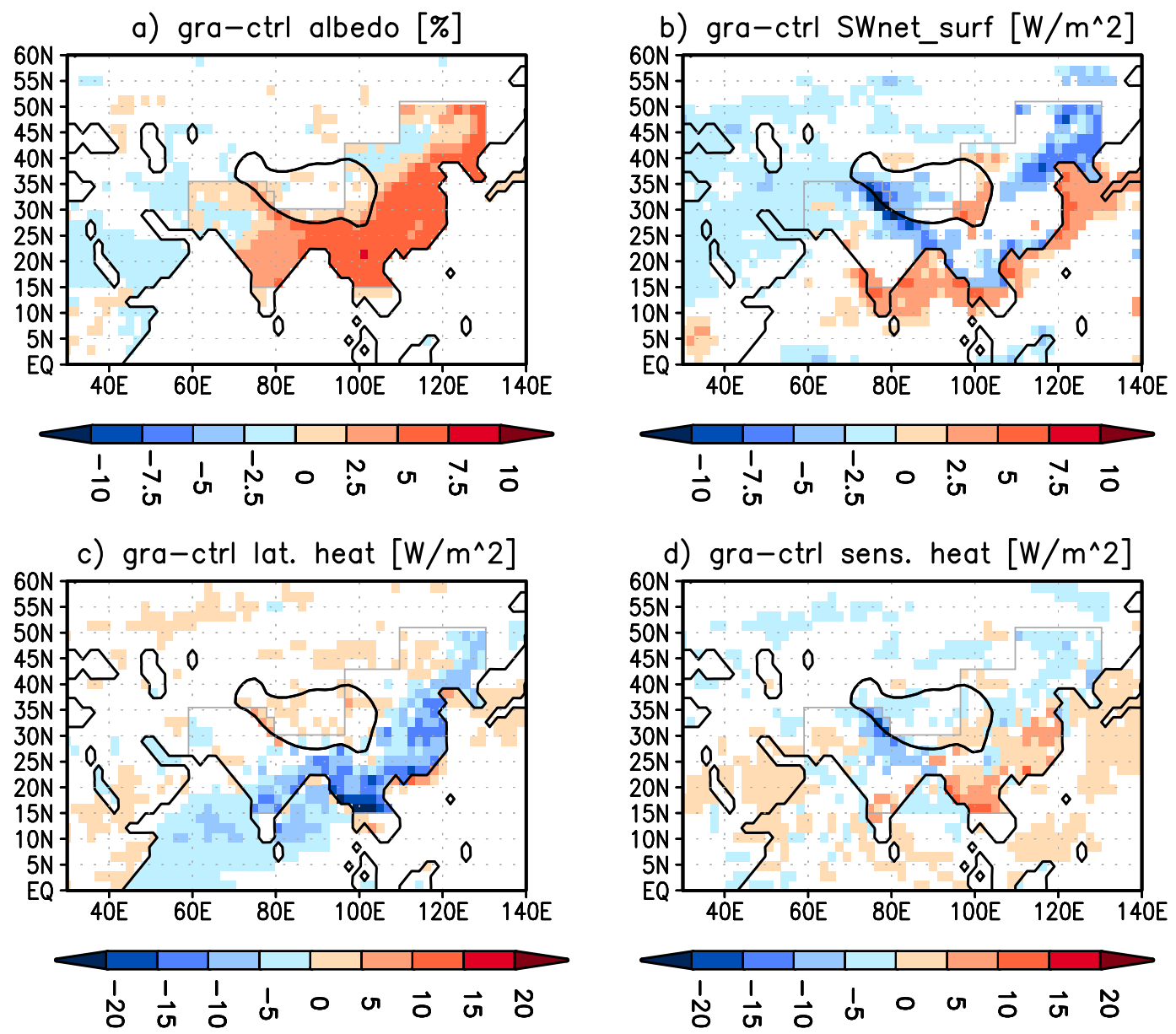

Fig. 11. Simulated change of different parameters influencing the temperature change between the deforestation experiment (gra) and the control run (ctrl), averaged over the monsoon season. For further details see Fig. 9.

Fleitmann et al., 2003; Wang et al., 2005; Maher, 2008) entailing shifts in precipitation pattern.

However, early human forest clearance might also have impacted the mid- to late-Holocene climate and land cover change. Conversely, climate and land cover change could strongly have influenced the development and decline of different prehistoric cultures in the Asian monsoon domain (cf. Fu, 2003; Clift and Plumb, 2008). The linkage between mid-Holocene climate, vegetation and human dynamics in the Asian monsoon region is therefore a scientific question worth to investigate.

As the Asian topography is very complex, the relatively sparse-distributed reconstructions can not necessarily represent the land cover in the entire region. Numerical experiments, for example conducted with the comprehensive Earth system model ECHAM5/JSBACH-MPIOM support the increase of vegetation and forest in the Asian monsoon domain under $6 \mathrm{k}$ climate conditions (Dallmeyer et al., 2010). But, compared to the available pollen records, the magnitude of Holocene vegetation change in these simulations seems to be underestimated. A complete picture of the mid-Holocene land cover in the Asian monsoon region and its change during the following millennia thus cannot be derived yet, neither from reconstructions nor from previous model-results.

To assess the biogeophysical impact of Holocene land cover change on the Asian monsoon climate we therefore chose an idealised approach: we assume that in midHolocene, the entire Asian monsoon domain was covered by forest and that mid- to late-Holocene climate change as well as early human forest clearance have altered the vegetation up to its present-day potential distribution. In other words, we repeat the afforestation and control experiment with the same boundary conditions with the exception that we prescribed mid-Holocene $(6 \mathrm{k}=6000 \mathrm{yr}$ before present $)$ insolation (FOR6k and CTRL6k). The biogeophysical effect of the idealised Holocene land cover change is then defined as the difference between the experiments "FOR6k" and "CTRL6k". 

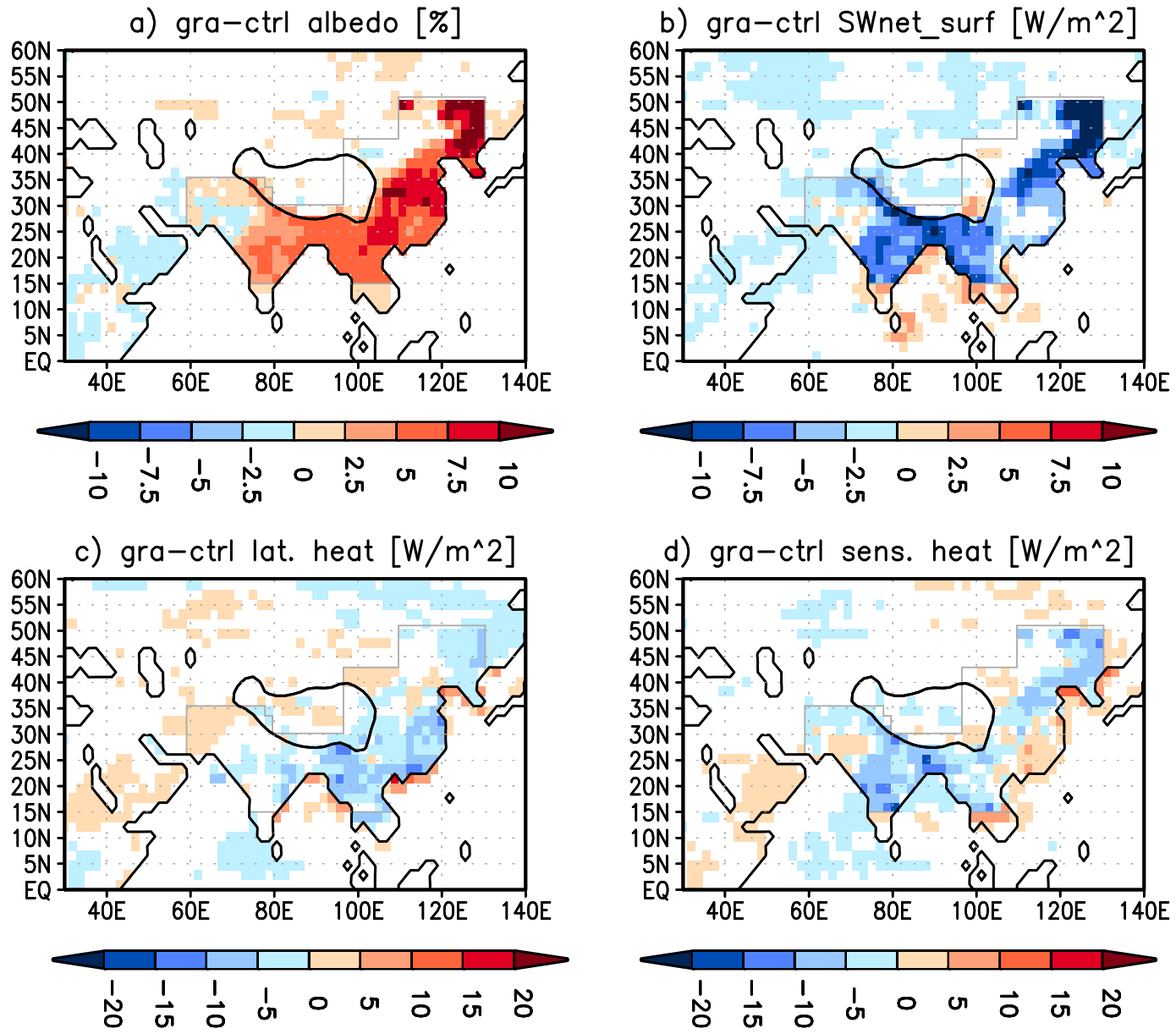

Fig. 12. Same as Fig. 11, but for the dry/cold season.

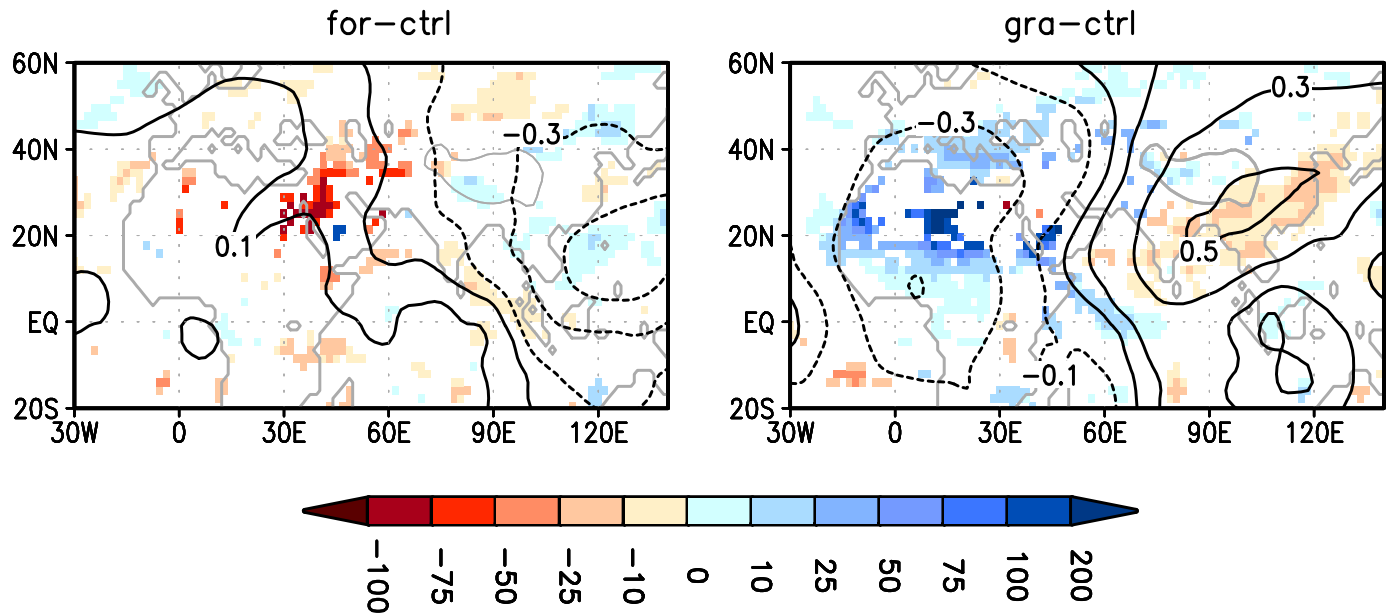

Fig. 13. Simulated change in monsoon season precipitation weighted by the precipitation of the control run in $\%$ (shaded) and simulated change in upper-tropospheric velocity potential in $\mathrm{km}^{2} \mathrm{~s}^{-1}$ (contour). Left panel: afforestation experiment (for) - control run (ctrl); right panel: deforestation experiment (gra) - control run (ctrl). Values are averaged over the monsoon season. Precipitation differences are only shown if they exceed the $95 \%$-significance level in a standard student's t-test. 
a) for $6 k-c t r l 6 k$ precip $[\mathrm{mm} /$ day $]$

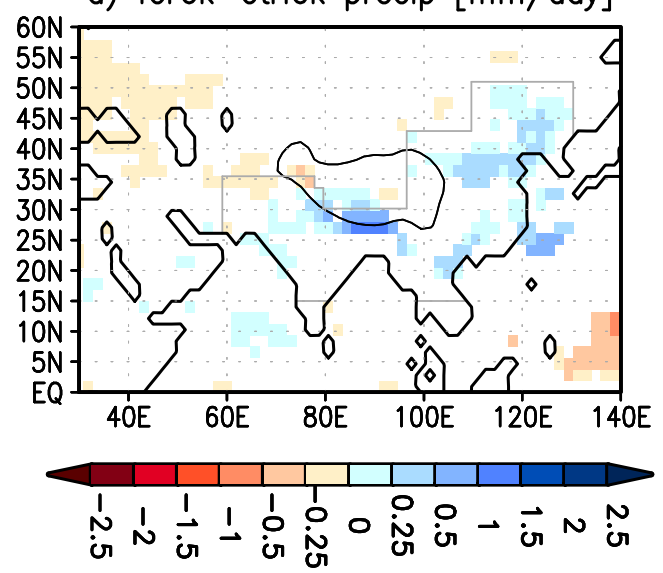

c) $\operatorname{ctr} 16 \mathrm{k}$ - ctrlok precip $[\mathrm{mm} /$ day $]$

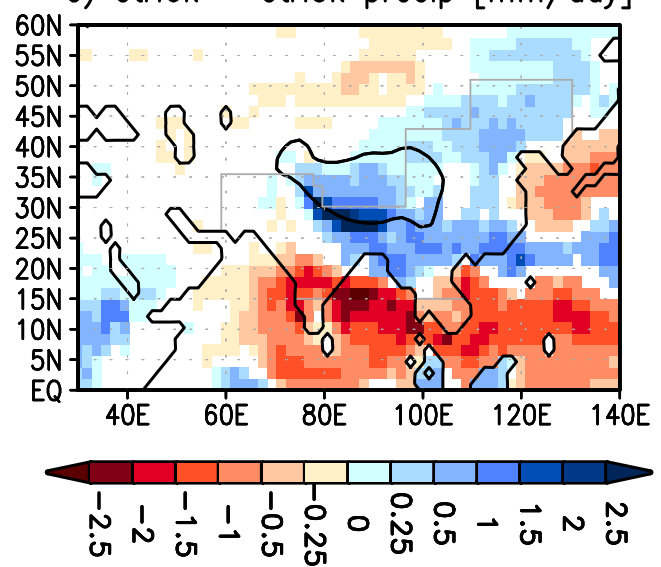

b) for-ctrl $6 \mathrm{k}-0 \mathrm{k}$ precip $[\mathrm{mm} /$ day $]$

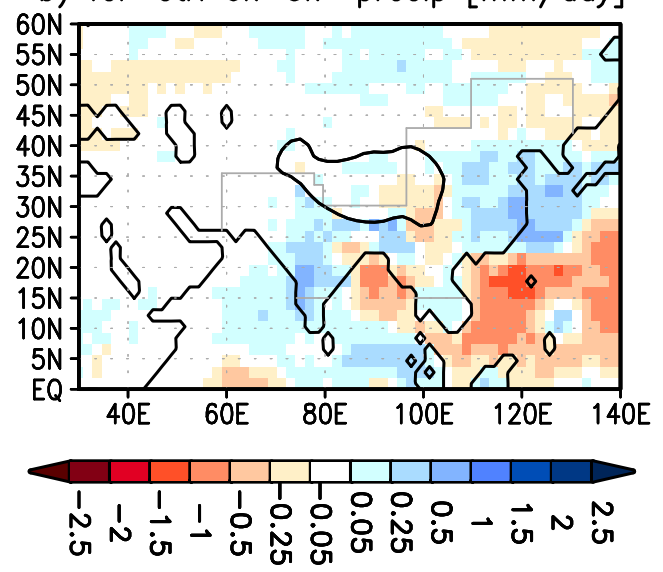

d) for-ctrl $6 k-0 k \quad p-e[\mathrm{~mm} /$ day $]$

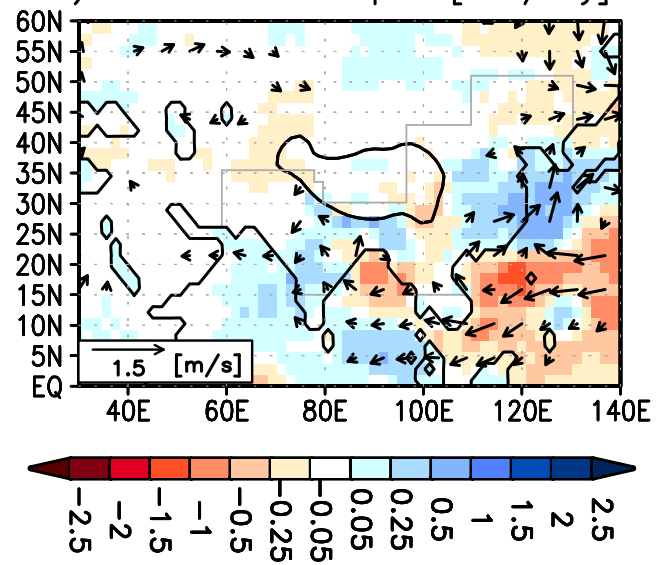

Fig. 14. Simulated precipitation change $\left[\mathrm{mm} \mathrm{day}^{-1}\right]$ between different experiments, averaged over the monsoon season: (a) significant (95\%, t-test) difference between the afforestation experiment (for) and the control run (ctrl) under mid-Holocene orbital conditions. (b) difference of the afforestation-induced climate signal (forctrl) between the simulations with mid-Holocene $(6 \mathrm{k})$ and present-day $(0 \mathrm{k})$ orbital condition. (c) significant (95\%, t-test) difference between the control run with mid-Holocene orbit and the control run with present-day orbit prescribed. (d) moisture convergence $\left[\mathrm{mm} \mathrm{day}^{-1}\right.$ ] between for-ctrl under $6 \mathrm{k}$-orbit and for-ctrl under $0 \mathrm{k}$-orbit combined with the difference in $850 \mathrm{hPa}$-wind $\left[\mathrm{m} \mathrm{s}^{-1}\right]$. Wind vectors with a magnitude of less than $0.15 \mathrm{~m} \mathrm{~s}^{-1}$ are not shown. Please note that the figures on the right panel do not only show significant values.

Figure 14a depicts the summer monsoon related precipitation difference between the afforestation and control experiment under $6 \mathrm{k}$-orbital conditions. Overall, the amplitude of monsoon precipitation change is similar as for $0 \mathrm{k}$-orbit (cf. Fig. 3, upper left panel), but the pattern of change is different. Afforestation has the same effect on precipitation at the south-central Tibetan Plateau (increase), the western Tibetan Plateau (decrease) and in Northeast China (increase), regardless which orbit is prescribed. However, under $6 \mathrm{k}$ orbital conditions, afforestation leads to more instead of less precipitation in south-eastern China (up to $0.2 \mathrm{~mm} \mathrm{day}^{-1}$ ) and significantly more precipitation in north-western India (up to $0.25 \mathrm{~mm} \mathrm{day}^{-1}$ ). Most striking is that precipitation is significantly increased by up to $0.45 \mathrm{~mm} \mathrm{day}^{-1}$ in the Shaanxi - Shandong region, where the prehistoric cultures settled.
To better visualise the different effect of afforestation under $6 \mathrm{k}$ - and $0 \mathrm{k}$-orbital conditions, Fig. 14b illustrates the difference of the afforestation-induced precipitation anomalies $(6 \mathrm{k}-0 \mathrm{k})$. It emphasises that afforestation leads to more precipitation in south- and central-eastern China as well as in India when mid-Holocene instead of present-day orbit is prescribed. These differences in precipitation signal can be related to a change in circulation and moisture convergence (Fig. 14d). With prescribed 6k-orbit, afforestation leads to a stronger monsoon flow anomaly onto the continent than under $0 \mathrm{k}$-orbital conditions. Therefore, more moisture is transported from the Pacific Ocean and Bay of Bengal to East China and India. 
Figure $14 \mathrm{c}$ shows the monsoon precipitation difference associated with the pure orbital forcing. Compared to this signal, the effect of afforestation on monsoon precipitation is weak. However, in the region with prehistoric settlement in eastern China, the precipitation change due to afforestation (6k) is approx. half as large as the change induced by the orbital forcing. Averaged over the region of ca. $99^{\circ} \mathrm{E}-120^{\circ} \mathrm{E}$ and $28^{\circ} \mathrm{N}-42^{\circ} \mathrm{N}$, afforestation leads to a precipitation increase of $0.14 \mathrm{~mm} \mathrm{day}^{-1}$. The orbital forcing results in $0.25 \mathrm{~mm} \mathrm{day}^{-1}$ additional precipitation.

According to our model results, large-scale Holocene forest decline, regardless, whether it has been climate- or human-induced, could thus strongly have contributed to the decrease in summer monsoon precipitation reconstructed for the East Asian monsoon region (e.g. Wang et al., 2005). However, the magnitude of the assumed forest loss in our study is intentionally exaggerated. The resulting climate signal can only be interpreted as a maximum effect. In comparison with the strong orbitally-induced climate signal, prehistoric deforestation might have been of no consequence. Nevertheless, according to our model results, one can not exclude that decreasing forest cover in the Asian monsoon region during the Holocene could have generated an additional environmental pressure on the Asian human civilisations by further reducing water availability.

\section{Summary and conclusion}

This study highlights the effect large-scale land cover change in the Asian monsoon domain could have on the regional and remote climate. By applying the general circulation model ECHAM5/JSBACH a set of numerical experiments has been performed with either complete forest cover or complete grass cover or potential present-day vegetation prescribed. Our analyses address the following questions: how do afforestation and deforestation influence the local climate? How large is the remote effect on precipitation in North Africa and the Middle East? Could early- and mid-Holocene land cover changes have contributed to the decreasing Asian monsoon precipitation known from reconstructions?

\section{a. Local effect:}

- The impact of land cover change on local precipitation is most pronounced in the monsoon season. During this time, deforestation leads to a broad reduction of precipitation in the Asian monsoon domain. In contrast, the change of precipitation resulting from afforestation is arranged in an alternating pattern: rainfall is decreased in South India and the Great Plain of China, while it is increased in south-eastern China, the southern part of the Tibetan Plateau and Northeast China.
- The precipitation signal can partly be related to changes in humidity and moisture convergence and are partly induced by a modification of the low level circulation and vertical motion.

- The impact of land cover change on local near-surface air temperatures is most pronounced in the dry/cold season. During this time, deforestation leads to a cooling and afforestation to a warming of the climate in most parts of the Asian monsoon domain. In the monsoon season, the signal is of similar shape in the regions with a rather temperate or cool climate, i.e. the northern parts. In the southern parts where climate is tropical, afforestation (deforestation) leads to a temperature decrease (increase) resulting from an enhanced (reduced) evaporative cooling.

- Most of the temperature signal can be explained directly by the change in surface albedo due to the land cover change and the accompanied alteration of the surface energy balance.

b. Remote effect:

- Changes in the Asian monsoon system can affect the climate in North Africa and the Middle East via the modification of the large-scale circulation. In our experiments, the remote effect of land cover change in the Asian monsoon domain on the precipitation pattern in these regions is strong with respect to the relative precipitation amount.

- According to our simulations, deforestation in the Asian monsoon domain significantly increases precipitation in most parts of North Africa. In some parts of the Sahara, rainfall is even doubled.

- Afforestation has no significant influence on African climate, but reduces precipitation in northern Arabia by up to $100 \%$. That means, large-scale afforestation in monsoonal Asia could lead to a complete cessation of summer rainfall in northern Arabia.

c. Role of Holocene land-cover change:

- The amplitude of the climate signal induced by afforestation does not change when prescribing midHolocene instead of present-day orbital conditions, but the pattern shifts, showing more precipitation in the region along the Yellow River.

- Compared to the climate change related to the orbital forcing, the overall climate signal induced by the land cover change is small in our model experiments. However, in the settlement area of East Asian prehistoric societies (mainly along the Yellow River) the precipitation change associated with the afforestation is half as large 

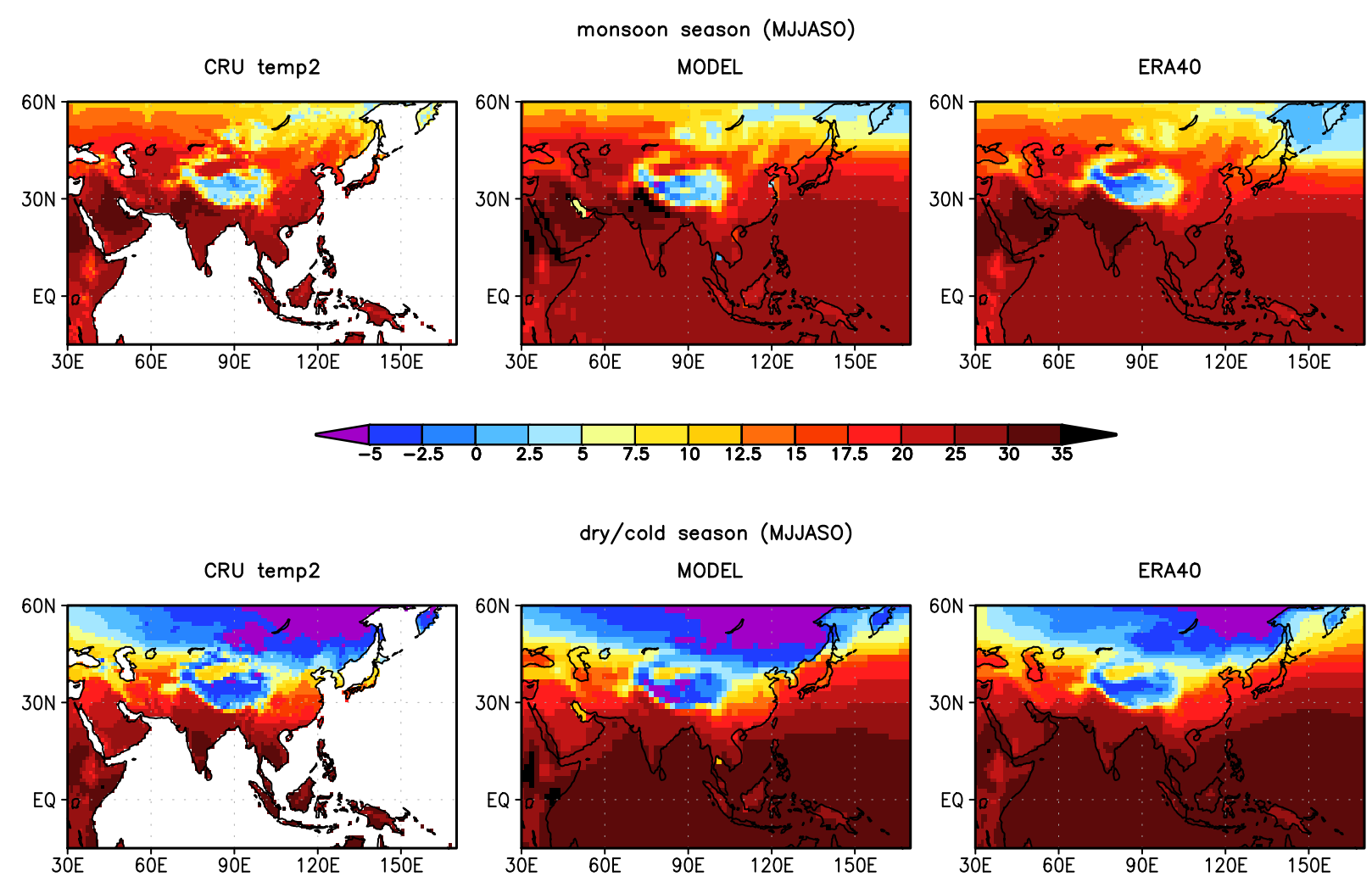

dry/cold season (MJJASO)

MODEL

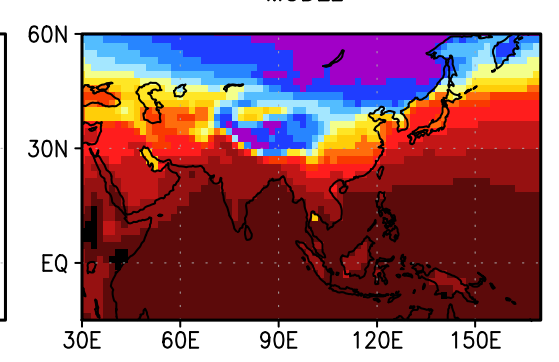

ERA40

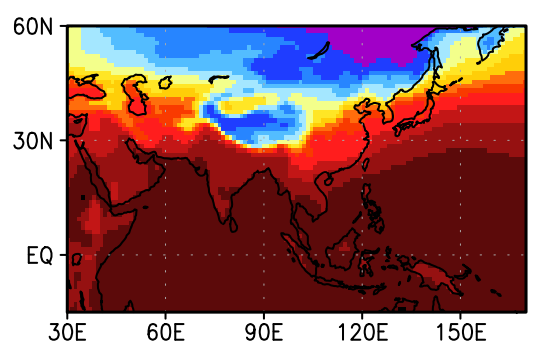

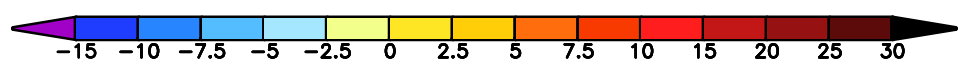

Fig. A1. Simulated near-surface air temperature $\left[{ }^{\circ} \mathrm{C}\right]$ compared to the observational dataset CRU TS 2.1 (Mitchell and Jones, 2005) and ERA40 reanalysis data (Simmons and Gibson, 2000), averaged over the monsoon season (May-October) and the dry/cold season (November-April). Values are taken from the CTRL simulation. CRU TS 2.1 does not include oceanic regions.

as the orbitally-induced precipitation change. In other words: under the assumption that the entire Asian monsoon region was covered by forest in early- and midHolocene, the loss of forest to the present-day potential land cover is responsible for more than one-third of the total mid- to late Holocene precipitation change in the settlement area of the major East Asian neolithic civilisations.

- The here prescribed complete forest cover is definitely an exaggerated representation of the mid-Holocene land cover in the Asian monsoon region. Therefore, the amplitude of the climate signal is probably too high.

- Our model results show that large-scale forest decline in East and South Asia leads to heavy losses in regional precipitation. One can not exclude that climateor human-induced land cover changes have contributed to the decline of major prehistoric civilisations by amplifying the general orbital-induced attenuating Asian summer monsoon.

\section{Appendix A}

\section{Simulated present-day Asian monsoon climate}

In this study, JSBACH functions as land-surface scheme of ECHAM5. In order to provide an overview on the representation of the present-day climate in ECHAM5/JSBACH, we compare key variables of the Asian monsoon climate system with observations and reanalysis data. Here, we show near-surface air temperature in two meters height (Fig. A1), annual mean precipitation (Fig. A2), mean sea level pressure and the wind circulation in $850 \mathrm{hPa}$ (Fig. A3).

Overall, the model is able to capture the observed temperature distribution and the monsoon circulation is well represented. Regarding precipitation, the model calculates a similar precipitation pattern as observed, but underestimates the annual mean precipitation in the Indian monsoon region. Furthermore, ECHAM5/JSBACH overestimates annual mean precipitation at the steep slopes of the Himalaya mountain range. 


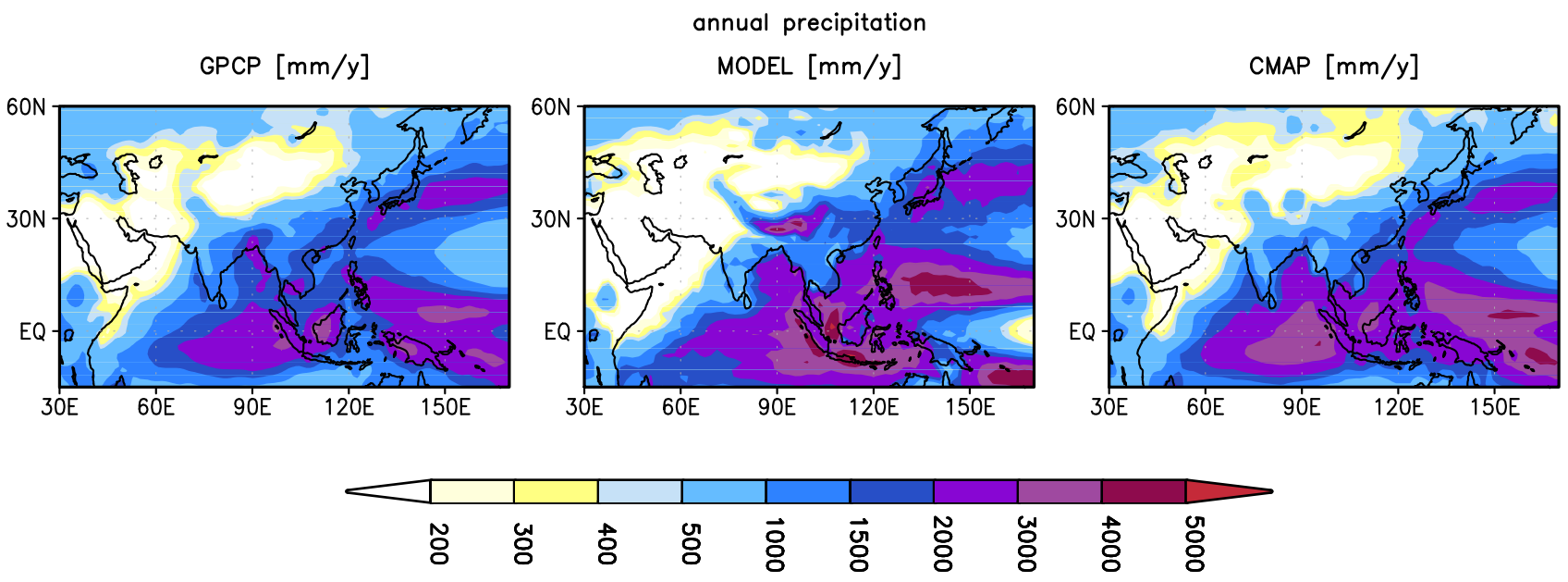

Fig. A2. Simulated annual precipitation $\left[\mathrm{mm} \mathrm{yr}^{-1}\right]$ compared to the observational datasets of GPCP (Adler et al., 2003) and CMAP (Xie and Arkin, 1997). Values are taken from the CTRL simulation.

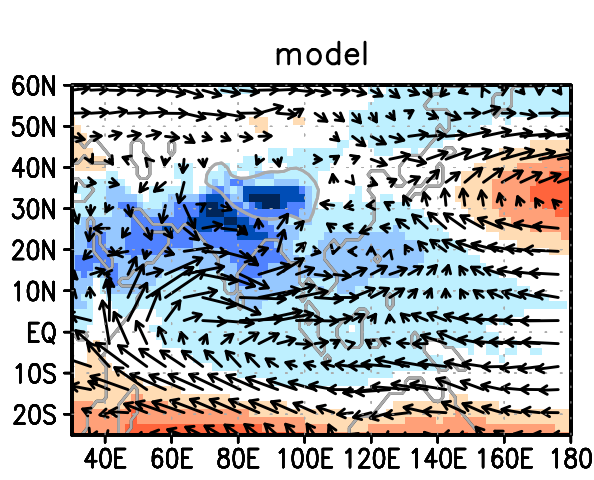

MJJASO

ERA40
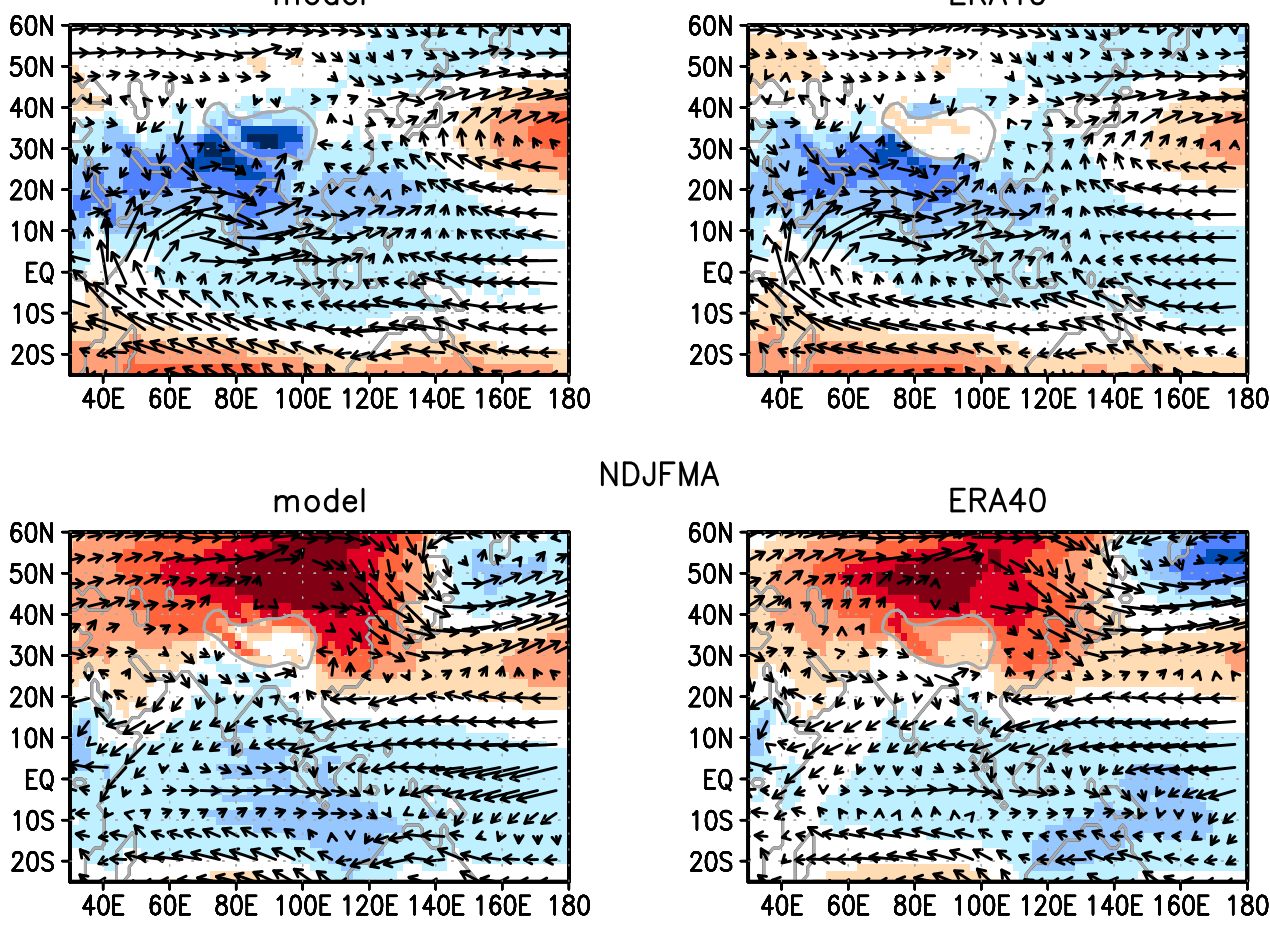

NDJFMA
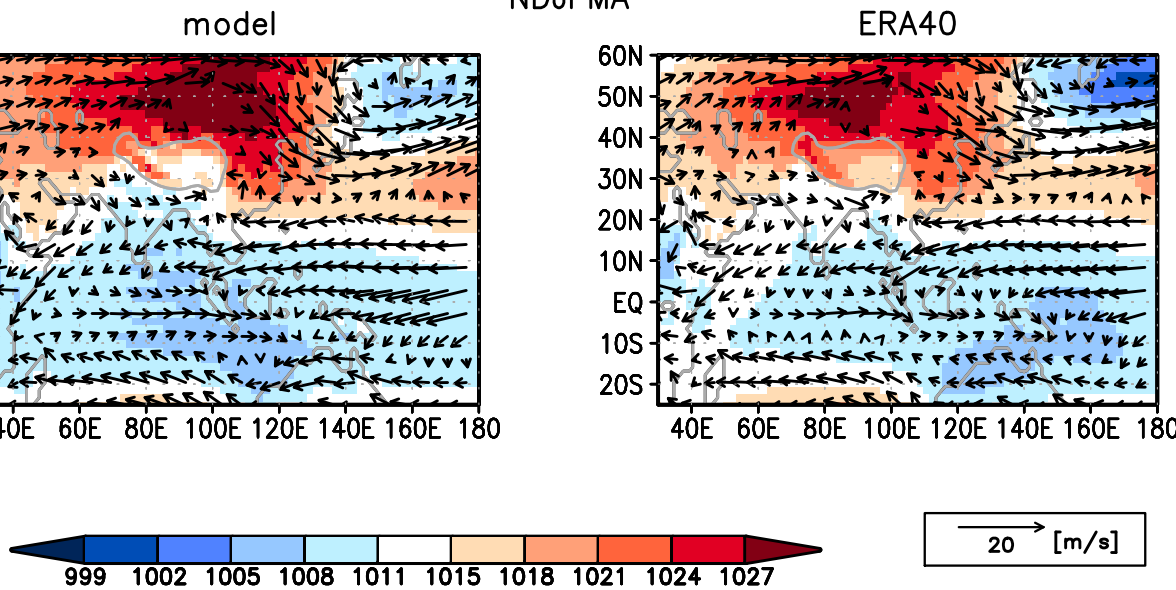

Fig. A3. Simulated mean sea level pressure in $\mathrm{hPa}$, shaded, and $850 \mathrm{hPa}$ wind circulation in $\mathrm{m} \mathrm{s}^{-1}$, vector, compared to ERA40 reanalysis data (Simmons and Gibson, 2000). Values are displayed as averages over the monsoon season (upper panel) and the dry/cold season (lower panel). Wind vectors are not shown in regions where the model orography exceeds $1500 \mathrm{~m}$. Values are taken from the CTRL simulation. 
Acknowledgements. This research was funded by the German Research Foundation (DFG, grant CL178/6-1,2). The authors would like to thank Victor Brovkin, MPI-M, for constructive discussion and two anonymous reviewers for their helpful comments which improved the manuscript.

The service charges for this open access publication have been covered by the Max Planck Society.

Edited by: A. Arneth

\section{References}

Adler, R. F., Huffman, G. J., Chang, A., Ferraro, R., Xie, P., Janowiak, J., Rudolf, B., Schneider, U., Curtis, S., Bolvin, D., Gruber, A., Susskind, J., Arkin, P., Nelkin, E.: The Version 2 Global Precipitation Climatology Project (GPCP) Monthly Precipitation Anaysis (1979-Present), J. Hydrometeor., 4, 11471167, 2003.

Ansari, M. and Vink, A.: Vegetation history and palaeoclimate of the past $30 \mathrm{kyr}$ in Pakistan as inferred from the palynology of continental margin sediments off the Indus Delta, Rev. Paleobot. Palynol., 145, 201-216, 2007.

Bathiany, S., Claussen, M., Brovkin, V., Raddatz, T., and Gayler, V.: Combined biogeophysical and biogeochemical effects of largescale forest cover changes in the MPI earth system model, Biogeosciences, 7, 1383-1399, doi:10.5194/bg-7-1383-2010, 2010.

Bonan, G. B.: Forests and climate change: Forcings, feedbacks, and the climate benefits of forests, Science, 320, 1444-1449, 2008.

Bonan, G. B., Pollard, D., and Thompson, S.L.: Effects of boreal forest vegetation on global climate, Nature, 359, 716-718, 1992.

Chalita, S. and Le Treut, H.: The albedo of temperate and boreal forest and the Northern Hemisphere climate: a sensitivity experiment using the LMD GCM, Clim. Dynam., 10, 231-240, 1994.

Claussen, M., Brovkin, V., and Ganopolski, A.: Biogeophysical versus biogeochemical feedbacks of large scale land cover change, Geophys. Res. Lett., 28, 1011-1014, 2001.

Clift, P. D. and Plumb, R.A.: The Asian monsoon: causes, history and effects, Cambridge Univ. Press, Cambridge, p. 270, 2008.

Dallmeyer, A., Claussen, M., and Otto, J.: Contribution of oceanic and vegetation feedbacks to Holocene climate change in monsoonal Asia, Clim. Past, 6, 195-218, doi:10.5194/cp-6-1952010, 2010.

Duan, A. and Wu, G. X.: Role of the Tibetan Plateau thermal forcing in the summer climate pattern over subtropical Asia, Clim. Dynam., 24, 793-807, 2005.

Findell, K. L., Knutson, T. R., and Milly, P. C. D.: Weak simulated extratropical responses to complete tropical deforestation, J. Climate, 19, 2835-2850, 2006.

Fleitmann, D., Burns, S. J., Mudelsee, M., Neff, U., Kramers, J., Mangini, A., and Matter, A.: Holocene forcing of the Indian monsoon recorded in a stalagmite from Southern Oman, Science, 300, 1737-1739, 2003.

$\mathrm{Fu}, \mathrm{C}$. : Potential impacts of human-induced land cover change on East Asia monsoon, Global Planet. Change, 37, 219-229, 2003.

Gao, X. J., Zhang, D. F., Chen, Z. X., Pal, J. S., and Giorgi, F.: Land use effects on climate in China as simulated by a regional climate model, Science in China Series D: Earth Sciences, 50(4), 620-628, 2007.

Gedney, N. and Valdes, P. J.: The effect of Amazonian deforestation on the Northern Hemisphere circulation and climate, Geophys. Res. Lett., 27, 3053-3056, 2000.

Hasler, N., Werth, D., and Avissar, R.: Effects of tropical deforestation on global hydroclimate: A multimodel ensemble analysis, J. Climate, 22, 1124-1141, 2009.

Henderson-Sellers, A., Dickinson, R. E. , Durbidge, T. B., Kennedy, P. J., McGuffie, K., and Pitman, A. J.: Tropical deforestation: Modeling local-scale to regional-scale climate change, J. Geophys. Res., 98(D4), 7289-7315, 1993.

Herzschuh, U., Birks, H. J. B., Ni, J., Zhao, Y., Liu, H., Liu, X., and Grosse, G.: Holocene land-cover changes on the Tibetan Plateau, The Holocene, 20, 91-104, 2010.

Ivory, S. and Lézine, A.-M.: Climate Environmental change at the end of the Holocene Humid Period: a pollen record off Pakistan, C. R. Geoscience, 341, 760-769, 2009.

Jungclaus, J. H., Botzet, M., Haak, H., Keenlyside, N., Luo, J.J., Latif, M., Marotzke, J., Mikolajewicz, U., and Roeckner, E.: Ocean circulation and tropical variability in the coupled model ECHAM5/MPI-OM, J. Climate, 19, 3952-3972, 2006.

Li, C. and Yanai, M.: The onset and interannual variability of the Asian summer monsoon in relation to land-sea thermal contrast, J. Clim., 9, 358-375, 1996.

Loveland, T. R., Reed, B. C., Brown, J. F., Ohlen, D. O., Zhu, Z., Yang, L., and Merchant, J. W.: Development of a global land cover characteristics database and IGBP DISCover from $1 \mathrm{~km}$ AVHRR data, Int. J. Remote Sens., 21, 1303-1330, 2000.

Maher, B. A.: Holocene variability of the East Asian summer monsoon from Chinese cave records: a re-assessment, The Holocene, 18(6), 861-866, 2008.

Marsland, S. J., Haak, H., Jungclaus, J. H., Latif, M., and Roske, F.: The Max-Planck-Institute global ocean/sea ice model with orthogonal curvilinear coordinates. Ocean Modell., 5, 91-127, 2003.

Mitchell, T. D and Jones, P. D.: An improved method of constructing a database of monthly climate observations and associated high-resolution grids, Int. J. Climatol., 25(6), 693-712, 2005.

Pielke, R. A., Avissar, R., Raupach, M., Dolman, A. J., Zeng, X. B., and Denning, A. S.: Interactions between the atmosphere and terrestrial ecosystems: influence on weather and climate, Glob. Change Biol., 4, 461-475, 1998.

Polcher, J. and Laval, K.: The impact of African and Amazonian deforestation on tropical climate, J. Hydrol., 155, 389-405, 389405, doi:10.1016/0022-1694(94)90179-1, 1994.

Polcher J, McAvaney, B., Viterbo, P., Baertner, M-A., Hahmann, A., Mahfouf, J.-F., Noilhan, J., Phillips, T., Pitman, A., Schlosser, C. A., Schulz, J-P., Timbal, B., Verseghy, D., and Xue, Y.: A proposal for a general interface between land surface schemes and general circulation models, Global Planet. Change, 19, 261276, 1998.

Pongratz, J., Reick, C., Raddatz, T., and Claussen, M.: A reconstruction of global agricultural areas and land cover for the last millennium, Global Biogeochem. Cy., 22, GB3018, doi:10.1029/2007GB003153, 2008.

Raddatz, T. J., Reick, C. H., Knorr, W., Kattge, J., Roeckner, E., Schnur, R., Schnitzler, K.-G., Wetzel, P., and Jungclaus, J.: Will the tropical land biosphere dominate the climate-carbon cycle 
feedback during the twenty-first century?, Clim. Dyn., 29, 565574, 2007.

Ramankutty, N. and Foley, J. A.: Estimating historical changes in global land cover: croplands from 1700 to 1992, Global Biogeochem. Cy., 13(4), 997-1027, 1999.

Ren, G.: Decline of the mid- to late Holocene forests in China: climatic change or human impact?, J. Quatern. Sci., 15(3), 273281, 2000.

Ren, G.: Changes in forest cover in China during the Holocene, Veget. Hist. Archaeobot., 16, 119-126, 2007.

Ren, G., and Beug, H-J.: Mapping Holocene pollen data and vegetation of China. Quat. Sci. Rev., 21, 1395-1422, 2002.

Rodwell, M. J. and Hoskins, B. J.: Monsoons ant the dynamic of deserts. Quart. J. Roy. Meteor. Soc., 122, 1385-1404, 1996.

Roeckner, E., Bäuml, G., Bonaventura, L., Brokopf, R., Esch, M., Giorgetta, M., Hagemann, S., Kirchner, I., Kornblueh, L., Manzini, E., Rhodin, A., Schlese, U., Schultzweida, U., and Tompkins, A.: The atmospheric general circulation model ECHAM5. Part I: Model description, MaxPlanckInst. f. Meteor., Report No. 349, Hamburg, 2003.

Simmons, A. J. and Gibson, J. K.: The ERA-40 Project Plan, ERA40 Project Report Series No. 1 ECMWF. Shinfield Park, Reading, UK, 63 pp., 2000.

Singh, G., Wasson, R. J., and Agrawal, D. P.: Vegetational and seasonal climate changes since the last full glacial in the Thar Desert, northwestern India, Rev. Paleobot. Palynol., 64, 351358, 1990.

Snyder, P. K.: The influence of tropical deforestation on the Northern Hemisphere climate by atmospheric teleconnections, Earth Interact., 14, 1-34, doi:10.1175/2010EI280.1, 2010.

Wang, Y. J., Cheng, H., Edwards, R. L., He, Y. Q., Kong, X. G., An, Z. S., Wu, J. Y., Kelly, M. J., Dykoski, C. A., and Li, X. D.: The Holocene Asian monsoon: Links to solar changes and North Atlantic climate, Science, 308, 854-857, 2005.

Webster, P. J., Magaòa, V. O., Palmer, T. N., Shukla, J., Tomas, R. A., Yanai, M., and Yasunari, T.: Monsoons: Processes, predictability, and the prospects for prediction, J. Geophys. Res., 103(C7), 14451-14510, 1998.
Werth, D. and Avissar, R.: The local and global effects of Amazonian deforestation, J. Geophys. Res., 107, 8087, doi:10.1029/2001JD000717, 2002.

Werth, D. and Avissar, R.: The local and global effects of Southeast Asian deforestation, Geophys. Res. Lett., 32, L20702, doi:10.1029/2005GL022970, 2005a.

Werth, D. and Avissar, R.: The local and global effects of African deforestation, Geophys. Res. Lett., 32, L12704, doi:10.1029/2005GL022969, 2005b.

Xie, P. and Arkin, P. A.: Global precipitation: A 17-year monthly analysis based on gauge observations, satellite estimates, and numerical model outputs, Bull. Amer. Meteor. Soc., 78, 25392558, 1997.

Yasunari, T.: Role of Land-Atmosphere Interaction on Asian Monsoon Climate, J. Meteorol. Soc. Jpn., 85B, 55-75, 2007.

Ye, D. Z. and Wu, G. X.: The role of the heat source of the Tibetan Plateau in the general circulation, Meteorol. Atmos. Phys., 67, 181-198, 1998.

Yu, G., Chen, X., Ni, J., Cheddadi, R., Guiot, J., Han, H., Harrison, S.P., Huang, C., Ke, M., Kong, Z., Li, S., Li, W., Liew, P., Liu, G., Liu, J., Liu, Q., Liu, K.-B., Prentice, I.C., Qui, W., Ren, G., Song, C., Sugita, S., Sun, X., Tang, L., Van Campo, E., Xia, Y., Xu, Q., Yan, S., Yang, X., Zhao, J., and Zheng, Z.: Palaeovegetation of China: a pollen date-based synthesis for the mid-Holocene and last glacial maximum, J. Biogeogr., 27, 635-664, 2000.

Zhao, Y., Yu, Z., and Chen, F.: Spatial and temporal patterns of Holocene vegetation and climate changes in arid and semi-arid China, Quat. Int., 194, 6-18, 2009.

Zhang, H. Q. and Gao X. J.: On the atmospheric dynamical response to land-use change in East Asian monsoon region, Clim. Dyn., 33, 409-426, 2008.

Zheng, Y. Q., Yu, G., Qian, Y. F., Miao, M., Zeng, X. M., and Liu, H. Q.: Simulations of regional climatic effects of vegetation change in China, Q. J. R. Meteorol. Soc., 128, 2089-2114, 2002. 